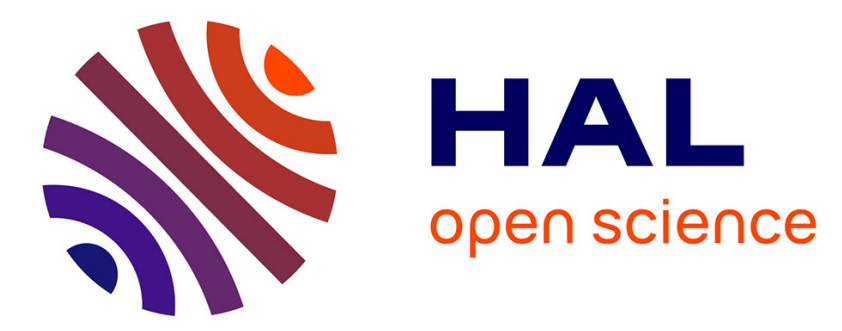

\title{
Dual-Doppler radar analysis of the enhancement of a precipitation system on the northern side of Mt. Halla, Jeju Island, Korea on 6 July 2007
}

Keun-Ok Lee, Hiroshi Uyeda, Shingo Shimizu, Dong-In Lee

\section{To cite this version:}

Keun-Ok Lee, Hiroshi Uyeda, Shingo Shimizu, Dong-In Lee. Dual-Doppler radar analysis of the enhancement of a precipitation system on the northern side of Mt. Halla, Jeju Island, Korea on 6 July 2007. Atmospheric Research, 2012, 118, pp.133-152. 10.1016/j.atmosres.2012.06.017 . hal-03269403

\section{HAL Id: hal-03269403 \\ https://hal.univ-reunion.fr/hal-03269403}

Submitted on 12 Aug 2021

HAL is a multi-disciplinary open access archive for the deposit and dissemination of scientific research documents, whether they are published or not. The documents may come from teaching and research institutions in France or abroad, or from public or private research centers.
L'archive ouverte pluridisciplinaire HAL, est destinée au dépôt et à la diffusion de documents scientifiques de niveau recherche, publiés ou non, émanant des établissements d'enseignement et de recherche français ou étrangers, des laboratoires publics ou privés. 


\title{
Dual-Doppler radar analysis of the enhancement of a precipitation system on the northern side of Mt. Halla, Jeju Island, Korea on 6 July 2007
}

\author{
Keun-Ok Lee $^{\mathrm{a}, *}$, Hiroshi Uyeda a ${ }^{\mathrm{a}}$, Shingo Shimizu ${ }^{\mathrm{b}}$, Dong-In Lee ${ }^{\mathrm{c}}$ \\ ${ }^{a}$ Hydrospheric Atmospheric Research Center, Nagoya University, Japan \\ ${ }^{\mathrm{b}}$ Dept. of Storm, Flood and Landslide Research, National Research Institute for Earth Science and Disaster Prevention, Japan \\ c Dept. of Environmental Atmospheric Sciences, Pukyong National University, Republic of Korea
}

\begin{abstract}
An elongated intense precipitation system associated with a stationary front delivered enhanced rainfall to the northern lateral and lee sides of an isolated mountain on Jeju Island on 6 July 2007. The convective region of the system passed around the mountain (Mt. Halla; height $1950 \mathrm{~m}$, width $35 \mathrm{~km}$, length $78 \mathrm{~km}$ ) under moist synoptic conditions (relative humidity $\sim 95 \%$ below $3 \mathrm{~km}$ ) during the rainy season. In this study, the detailed 3-dimensional structure and enhancement mechanisms of this precipitation system are examined using dual-Doppler radar observations. Analysis of the Doppler radar indicates that the precipitation system was organized in an elongated shape that extended southwest-northeast about $20 \mathrm{~km}$ off the northwestern shore of Jeju Island. The development of this precipitation system with respect to Mt. Halla can be divided into three stages: approaching stage, lateral-side stage, and lee-side stage. During the approaching stage, variational wind analysis indicates that the updraft region was aligned with the convergence zone of relatively strong westerlies and weak southwesterlies on the western side of the system. The southwesterlies accelerated gradually, generating local updrafts between the system and the northwestern slope of the mountain that were crucial to the enhancement of the southern part of the system. The enhanced convective region intensified further as it reached the northwestern shore of the island. The elliptical shape and isolated terrain of Jeju Island played an important role in this intensification by modifying the low-level winds, with a relatively low Froude number of 0.2 . This modification of the low-level wind by the terrain provided a plentiful supply of moist air to the convective region of the system, maintaining the enhanced convection. During the lee-side stage, the system was characterized by relatively weak westerlies at low altitude as it approached the eastern slope of the mountain. The convergence of these weak westerlies and relatively strong southwesterlies over the southeastern slope of the mountain induced a stationary updraft region and re-enhancement of convection on the lee-side of the mountain. The regional enhancement of this precipitation system on the lateral and lee sides of Mt. Halla resulted from localized terrain-induced low-level convergence under moist environmental conditions with predominant west-southwesterly winds. These environmental conditions are well organized when a stationary front is located off the northern shore of Jeju Island.
\end{abstract}

\footnotetext{
* Corresponding author at: \#528, Hydrospheric Atmospheric Research Center, Nagoya University, F3-1(200), Furo-cho, Chikusa-ku, Nagoya, Japan. Tel.: +81 527893492; fax: +81 527893436 .

E-mail address: leeko@rain.hyarc.nagoya-u.ac.jp (K-O. Lee).
}

\section{Introduction}

Orography plays an important role in controlling cloud formation and the amount and distribution of associated precipitation (Lin, 2007). A number of previous studies have aimed to improve understanding of the mechanisms important to orographically induced precipitation systems, 
examining factors such as low-level convergence, wind blocking (measured by the Froude number, Fr), ambient wind direction and speed, steepness of the topography, environmental stability, and latent heating and cooling processes induced by various shapes and sizes of terrain (Smith, 1979; Smolarkeiwicz et al., 1988; Smolarkeiwicz and Rotunno, 1989; Li et al., 1997; Olafsson, 2000; Chiao and Lin, 2003; Jiang, 2003). The shape and size of topography has a profound effect on the ultimate distributions of wind flow and precipitation (Houze, 2011). Extensive theoretical studies have used numerical simulations to evaluate the terrain-modified airflow around isolated bell-shaped topography (Smith, 1980; Smolarkeiwicz et al., 1988; Smolarkeiwicz and Rotunno, 1989, 1990; Jiang, 2003). These studies have shown that the windward side of the obstacle is characterized by a convergence zone, with a flow reversal on the windward slope of the mountain if it is high. Lee vortices, which are closely associated with gravity wave dynamics, form on the lee side of the mountain.

Distinctive terrain-modified airflows appear around isolated topography with an elliptical shape. Several previous theoretical studies have used numerical experiments to show the mechanisms by which airflow is modified around isolated elliptically shaped topography (Georgelin and Richard, 1996; Olafsson and Bougeault, 1996, 2000; Petersen et al., 2003, 2005). Based on these results, a mountain that is elongated in the direction perpendicular to the flow diverts and concentrates the low-level wind on the elongated windward side of the mountain. Eddy shedding and a sea level pressure deficit occur offshore to the lee side of the mountain.

When a moist airflow enters a mountainous area, the flow is modified by orographic lifting and blocking that may modify and/or trigger cloud and precipitation systems in the vicinity. Most previous studies of these effects have been based on a theoretical and numerical approach; few studies have used an observational approach. Furthermore, the few studies that employed an observational approach have focused on a small subset of the mountainous regions that occur worldwide. It remains important to examine how orographic precipitation systems vary spatially and temporally in the presence of a variety of shapes and sizes of terrain, and to extend understanding of the mechanisms underlying orographically enhanced precipitation systems.

Wang et al. (2005) analyzed radar observations and the results of numerical experiments to investigate the effect of elliptically shaped topography in Taiwan's central mountain region (CMR; height $4 \mathrm{~km}$, width $120 \mathrm{~km}$, length $320 \mathrm{~km}$ extending southwest-northeast) on convective enhancement during the rainy season. Their results indicated that a predominant westerly wind toward the western CMR was blocked by the terrain, changing the westerly wind to a southwesterly wind that blew parallel to the elongated terrain. Under this wind configuration, a convective line oriented southwest-northeast slowly approached the northwest CMR from the nearby ocean. The southern part of this convective line was subsequently significantly enhanced by additional convergence due to terrain blocking, resulting in heavy rainfall (nearly $200 \mathrm{~mm}$ over $2 \mathrm{~h}$ ) along the northwestern coast of Taiwan.

Similar to Taiwan, Jeju Island has frequently suffered from flooding and landslides due to orographically intensified precipitation systems during the rainy season (June to mid-July). Jeju Island is located in the southern part of Korea, and has a small but steep elliptically shaped terrain (height $1950 \mathrm{~m}$, width $35 \mathrm{~km}$, length $78 \mathrm{~km}$ ) that extends west-east. Lee et al. (2010) investigated the mechanisms of an orographically enhanced precipitation system that occurred at Jeju Island on 30 June 2006 using a single Doppler radar and the results of a numerical experiment. The precipitation system moved from the western part to the northeastern part of the island under a predominant westerly wind. The system intensified significantly on the northwestern lateral side of the island due to flow blocking by the terrain and the resulting modification of the wind to southwesterly. Simultaneously, a portion of the westerly wind flowed over the mountain and induced a downdraft region on the lee side of the island, resulting in the dissipation of the system. Their study showed that the topography of Jeju Island and the moist environment that prevails on the island during the rainy season play important roles in generating localized intense rainfall on the northwestern lateral side of the island. The limited observational area of single Doppler radar did not provide a full description of the 3-dimensional structure of the precipitation system around Jeju Island, however. This limitation underscores the importance of dual-Doppler radar observations for further understanding of precipitation systems that occur around topographic features like Jeju Island.

Several field experiments of dual-Doppler radar observation in the inland of China to Japan investigated the structure of meso- $\alpha$-scale convective systems (horizontal scale of $200-2000 \mathrm{~km}$ ) along a stationary front (Baiu/Meiyu front) which is composed of several meso- $\beta$-scale (horizontal scale of 20-200 km; Olanski, 1975) convective rainbands which are inducing heavy rainfall in rainy season (e.g., Ogura, 1991; Yamada et al., 2003; Geng et al., 2009). The sophisticated structure and triggering for the system enhancement are revealed to be different over distinct geographic locations (e.g., Chen and Chang, 1980; Kato, 1985; Ninomiya and Muraki, 1986).

The Korea Meteorological Administration (KMA) began to operate two S-band Doppler radars at Gosan (GSN, west) and Seongsan (SSN, east) on Jeju Island in 2007, making it possible to examine precipitation systems on Jeju Island using dual-Doppler radar observations. On 6 July 2007, an elongated intense precipitation system passed through the observation area, delivering a relatively high rainfall amount $(25 \mathrm{~mm}$ over $1.5 \mathrm{~h})$ on the northern lateral side of the mountain. The system had a similar distribution of precipitation to that associated with the system analyzed by Lee et al. (2010). The maximum accumulated rainfall $(35 \mathrm{~mm})$ associated with this system was recorded on the northeastern part of the island. In this study, we use a dual-Doppler radar analysis to describe the evolution of the detailed 3-dimensional structure of reflectivity and wind in the 6 July 2007 precipitation system and to reveal the mechanisms that led to its enhancement.

\section{Observational data and analysis methods}

An intense precipitation system occurred at Jeju Island on 6 July 2007. This system was observed by two Doppler radars 
(open circles Fig. 1) and 17 surface rain gauges (dots in Fig. 2). Fig. 2 shows the accumulated rainfall amount as the system passed around an isolated mountain on Jeju Island, from 0000 to 0130 LST (local standard time; LST $=$ UTC $+9 \mathrm{~h}$ ). Only $5 \mathrm{~mm}$ of accumulated rainfall was recorded on the western side of the island, while $25 \mathrm{~mm}$ was recorded on the northern side of the island. The maximum accumulated rainfall amount $(35 \mathrm{~mm})$ was recorded on the northeastern part of the island.

As shown in Fig. 1, two S-band Doppler radars are operated by KMA on Jeju Island, one at GSN (west) and one at SSN (east). The distance between the two radar stations is $65 \mathrm{~km}$. KMA also conducts upper-air soundings at GSN, from the same site as the GSN radar. The dual-Doppler radars, which each cover a radius of $250 \mathrm{~km}$ (Nyquist velocity of $63.17 \mathrm{~m} \mathrm{~s}^{-1}$ ) and together cover all of Jeju Island, record volume scans of reflectivity and Doppler velocity (radius $120 \mathrm{~km}$ ) every $10 \mathrm{~min}$. The two Doppler radars have identical specifications, with sampling resolutions of $500 \mathrm{~m}$ in the radial direction and $1.0^{\circ}$ in the azimuthal direction. Each volume scan includes observations at 15 elevation angles $\left(0.5^{\circ}, 0.6^{\circ}, 0.8^{\circ}, 1.0^{\circ}, 1.5^{\circ}, 2.0^{\circ}, 2.5^{\circ}, 3.5^{\circ}, 4.5^{\circ}, 6.0^{\circ}, 7.8^{\circ}, 10.5^{\circ}\right.$, $13.7^{\circ}, 18.1^{\circ}$, and $24.0^{\circ}$ ). The dual-Doppler radar data are interpolated into a Cartesian coordinate system with vertical grid intervals of $0.25 \mathrm{~km}$ and horizontal grid intervals of $1.0 \mathrm{~km}$ (CAPPI dataset). A Cressman-type weighting function is used for the interpolation with the fixed horizontal and vertical effective radius of influence of 1.5 and $1.0 \mathrm{~km}$, respectively (Cressman, 1959). The moving direction and speed of the precipitation system are reflected in CAPPI dataset for gaining the system-relative wind field.

The three Cartesian components of wind are calculated within the dashed circles, except in the intersection area specified in Fig. 1 (intersection angle $35^{\circ}$ ). The dual-Doppler radar analysis is conducted using the variational method

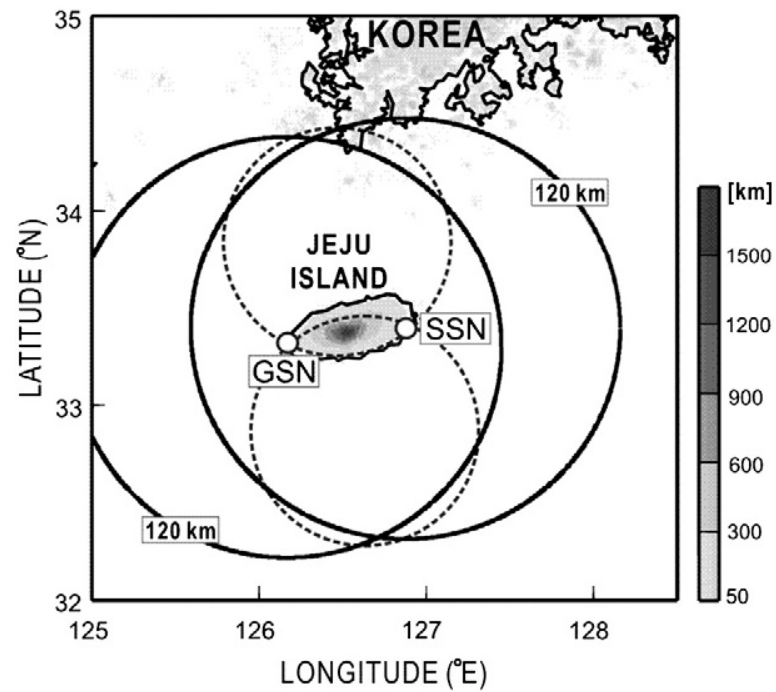

Fig. 1. Elevation map of Jeju Island and observational range $(120 \mathrm{~km}$; black circles) of the dual-Doppler radars installed at Gosan (GSN) and Seongsan (SSN). The GSN and SSN radar sites are indicated by small open circles. The upper-air sounding station is located at the GSN radar site. Dual-Doppler radar analysis is conducted within the two dashed circles, except for within the area of intersection (intersection angle less than $35^{\circ}$ ).

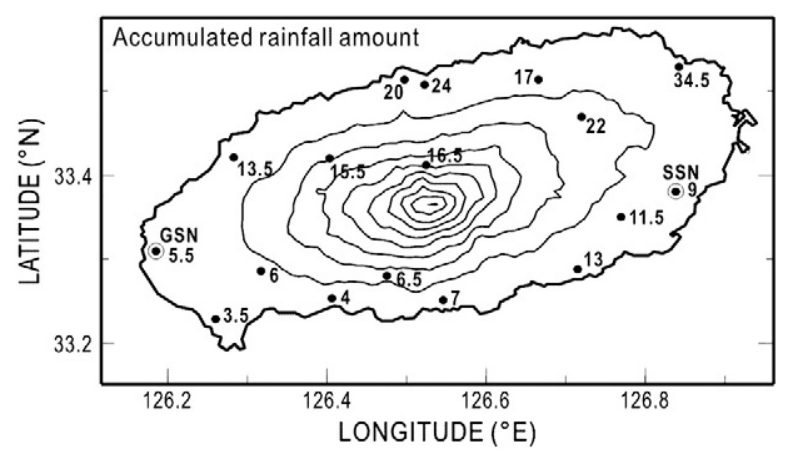

Fig. 2. Accumulated rainfall amount recorded by 17 rain gauges (dots) on Jeju Island from 0000 to 0130 LST on 6 July 2007. Thin contour lines show topography (contour interval: $200 \mathrm{~m}$ ). The locations of the two radar sites (GSN and SSN) are indicated by small open circles.

introduced by Gao et al. (1999). The boundary condition is specified as $w=0 \mathrm{~ms}^{-1}$ at $\mathrm{z}=0.5 \mathrm{~km}$ and the precipitation system top. The observed radar reflectivity at the top of the system was sufficiently weak (less than $15 \mathrm{dBZ}$ ) to assume $0 \mathrm{~ms}^{-1}$ vertical velocity. The parameter settings are identical to those used by Gao et al. (1999): $\lambda_{o}=1, \lambda_{d}=1.0 \times 10^{5}, \lambda_{u s}=$ $\lambda_{v s}=\lambda_{u w}=5.0 \times 10^{3}$, and $\lambda_{b}=0$. The calculation error in the vertical velocity is large at upper levels because of signal noise. To account for this uncertainty, airflows are shown only below $6 \mathrm{~km}$ above sea level (ASL) and the description of the airflow structure focuses only on the lower and middle levels of the precipitation system.

In this paper, the area of radar reflectivity stronger than $45 \mathrm{dBZ}$ at $2 \mathrm{~km}$ ASL is referred to as the "convective region." This region corresponds to the region of intense rainfall.

Meso-scale model (MSM) data provided by Japan Meteorological Agency (JMA) is employed to gain additional understanding of the synoptic moisture environment. The JMA-MSM output is provided at a horizontal resolution of $5 \mathrm{~km}$ with $253 \times 241$ grid points and 16 vertical $\sigma$ levels.

Several environmental parameters are calculated from the upper-air sounding data recorded at GSN (Fig. 1), including precipitable water (PW) from the surface to $700 \mathrm{hPa}$ (lowlevels), $\mathrm{PW}$ from 700 to $400 \mathrm{hPa}$ (mid-levels), surface relative humidity (RH), the lifting convection level (LCL), and the level of free convection (LFC). Froude number (Fr) was calculated using mean wind velocities obtained from the upper-air sounding data (see Table 1). Fr, which is proportional to the square root of the ratio of kinetic energy of the upstream parcel to the energy required to lift the fluid

Table 1

Environmental parameters determined from upper-air sounding data obtained at GSN at 2100 LST on 5 July 2007: lifting condensation level (LCL), level of free convection (LFC), surface relative humidity (RH), calculated precipitable water (PW) from the surface to $700 \mathrm{hPa}$, BruntVäisälä frequency $(\mathrm{N})$, and Froude number $(F r)$.

\begin{tabular}{ll}
\hline Parameter & Value \\
\hline LCL & $922.9 \mathrm{hPa}$ \\
LFC & $680 \mathrm{hPa}$ \\
RH (surface) & $94 \%$ \\
PW (below 700hPa) & $41.7 \mathrm{kgm}^{-2}$ \\
$\mathrm{~N}$ & $1.7 \times 10^{-2} \mathrm{~s}^{-1}$ \\
$\mathrm{Fr}$ & 0.2 \\
\hline
\end{tabular}


element over the terrain, is a dimensionless parameter defined as follows:

$F r=U_{0} / N h$

where $U_{0}$ is the averaged wind speed below the maximum height of the terrain, $N$ is the Brunt-Väisälä frequency, and $h$ is the height of the mountain $(1,950 \mathrm{~m}) . U_{0}$ and $N$ are representative of the environment in the atmospheric interval between the ground surface and the height of Mt. Halla. A low $\mathrm{Fr}(<0.5)$ tends to induce intense clouds and a nearly horizontal detour of the fluid around the obstacle, while a large $\operatorname{Fr}(\geq 1.0)$ tends to induce a vertically propagating wave (Smolarkeiwicz et al., 1988; Smolarkeiwicz and Rotunno, 1989, 1990; Yoshizaki et al., 2000).

Table 1 lists the environmental parameters obtained from an upper-air sounding launched at GSN a few hours prior to the approach of the precipitation system. A near-saturated layer of air ( $\mathrm{RH} 94 \%$ ) was observed near the surface, with relatively high PW $\left(41.7 \mathrm{~kg} \mathrm{~m}^{-2}\right)$ from the surface to $700 \mathrm{hPa}$. Approximately $65 \%$ of the moisture content concentrated in the low-levels. The lifting condensation level (LCL) was located at $922.9 \mathrm{hPa}$. By contrast, the PW at mid-levels $(700-400 \mathrm{hPa})$ was relatively low $\left(19.8 \mathrm{~kg} \mathrm{~m}^{-2}\right) . \mathrm{Fr}$ was calculated to be 0.2 under these relatively moist low-level conditions at Jeju Island, indicating that the airflow was unlikely to pass over the mountain (Yoshizaki et al., 2000).

\section{Precipitation system of 6 July 2007}

On 6 July 2007, an elongated intense precipitation system passed through the observation area of the dual-Doppler radars between 0000 and 0130 LST. Fig. 3 shows a surface weather map over East Asia at 0300 LST on 6 July 2007. A stationary front (the Changma/Baiu/Meiyu front) was located slightly north of Jeju Island. The horizontal distribution of RH at $950 \mathrm{hPa}$ (Fig. 4a) shows that a band-shaped moist region ( $\mathrm{RH}$ exceeding 94\%) covered the southern Korean peninsula at 0000 LST on 6 July 2007. The winds at 950 hPa near Jeju Island were southwesterly and relatively weak $\left(5 \mathrm{~ms}^{-1}\right)$. At $700 \mathrm{hPa}$ (Fig. 4b), the RH over the island was high (97\%) and the winds were westerly and relatively strong $\left(\sim 20 \mathrm{~ms}^{-1}\right)$.

The horizontal distributions of reflectivity at $2 \mathrm{~km}$ ASL are shown for every 10 minutes between 0000 and

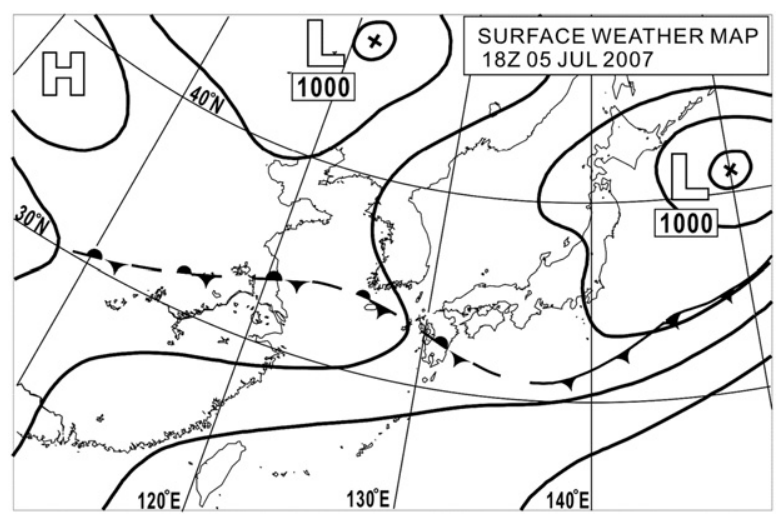

Fig. 3. Surface weather map covering East Asia at 0300 LST on 6 July 2007.
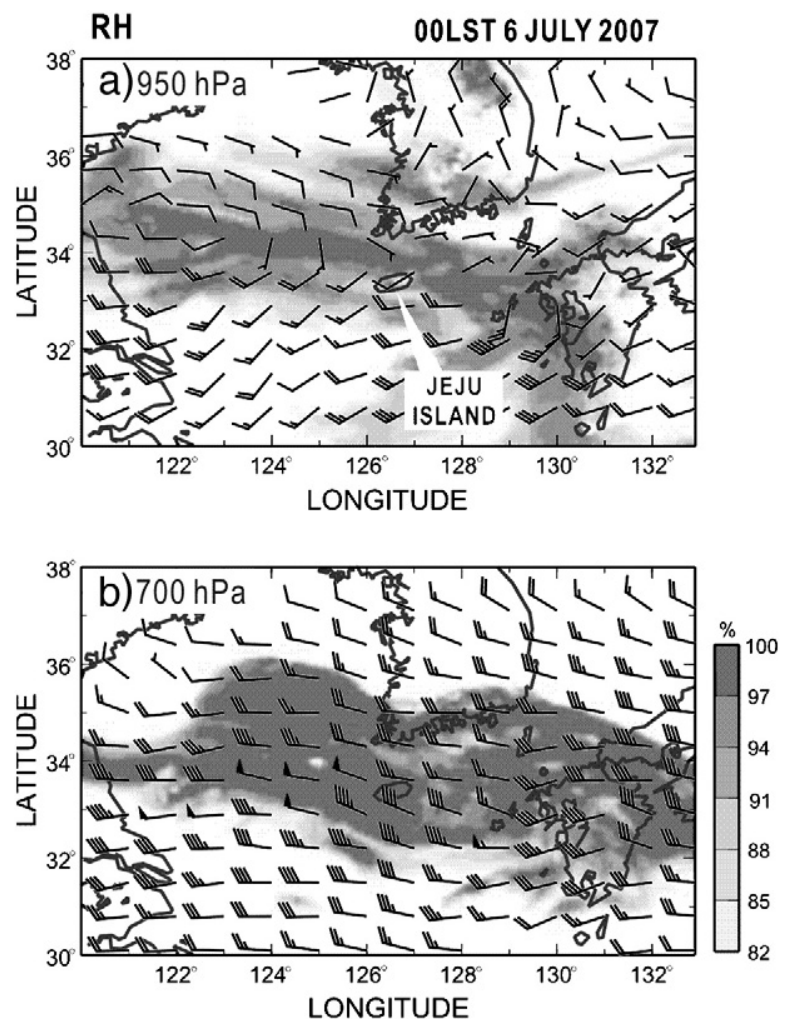

Fig. 4. Distributions of relative humidity $(\mathrm{RH})$ and horizontal wind at (a) $950 \mathrm{hPa}$ and (b) $700 \mathrm{hPa}$ at 0000 LST on 6 July 2007.

0130 LST in Fig. 5. At 0000 LST (Fig. 5a), the convective region (radar reflectivity $>45 \mathrm{dBZ}$ ) of the precipitation system was located approximately $20 \mathrm{~km}$ from the northwestern shore of the island. The convective region intensified as it approached the northwestern shore of the island during 0010-0030 LST (Fig. 5b-d), then moved eastward during 0040-0050 LST (Fig. 5e-f), passing around the northern part of the island and continuing to intensify. The precipitation system was located over the northeastern part of the island at 0100 LST (Fig. 5g), while the enhanced convective region persisted over the northern coast (20-30 km north of GSN). By contrast, the convective region off the northern coast of the island ( $30-50 \mathrm{~km}$ north of GSN) was relatively weak by this time. The convective region moved to the eastern slope of the island (10-25 km north of GSN) and re-intensified during 0110-0120 LST (Fig. 5h-i), while the convective region off the northeastern coast of the island $(30-50 \mathrm{~km}$ north of GSN) weakened even further. By 0130 LST (Fig. 5j), the convective region was located off the eastern shore of the island and relatively weak.

To show the horizontal evolution of the convective region depending on the relative location to Jeju Island, four analysis domains were selected within a $40 \mathrm{~km} \times 10 \mathrm{~km}$ area north of GSN that includes the convective region. These domains are referred to as $\mathbf{N 1}$ (10-20 km north of GSN over mountainous area), N2 (20-30 km north of GSN over the northern coast), N3 (30-40 km north of GSN just off the northern coast), and N4 (40-50 km north of GSN over open sea). These analysis domains are shifted at the same speed as the system 
$2 \mathrm{~km}$ CAPPI 6 JULY 2007
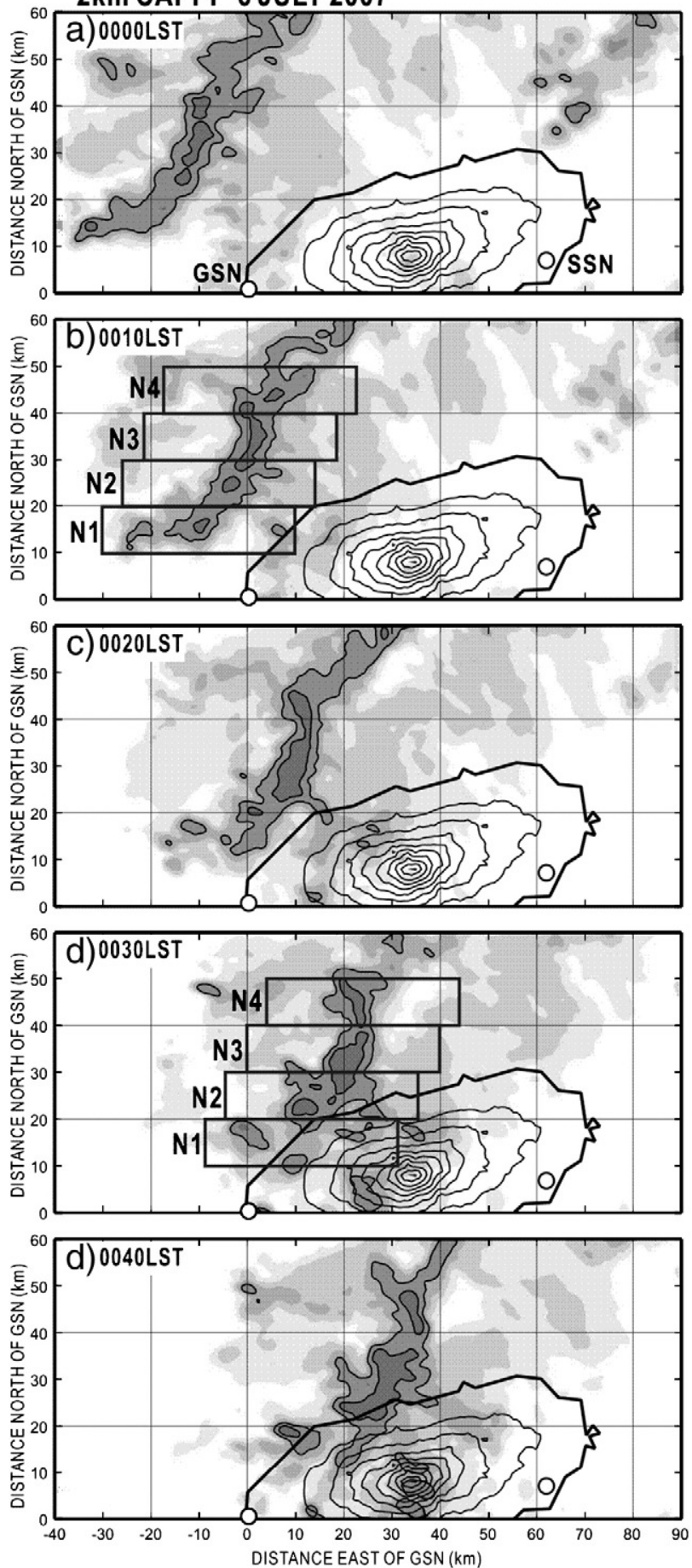
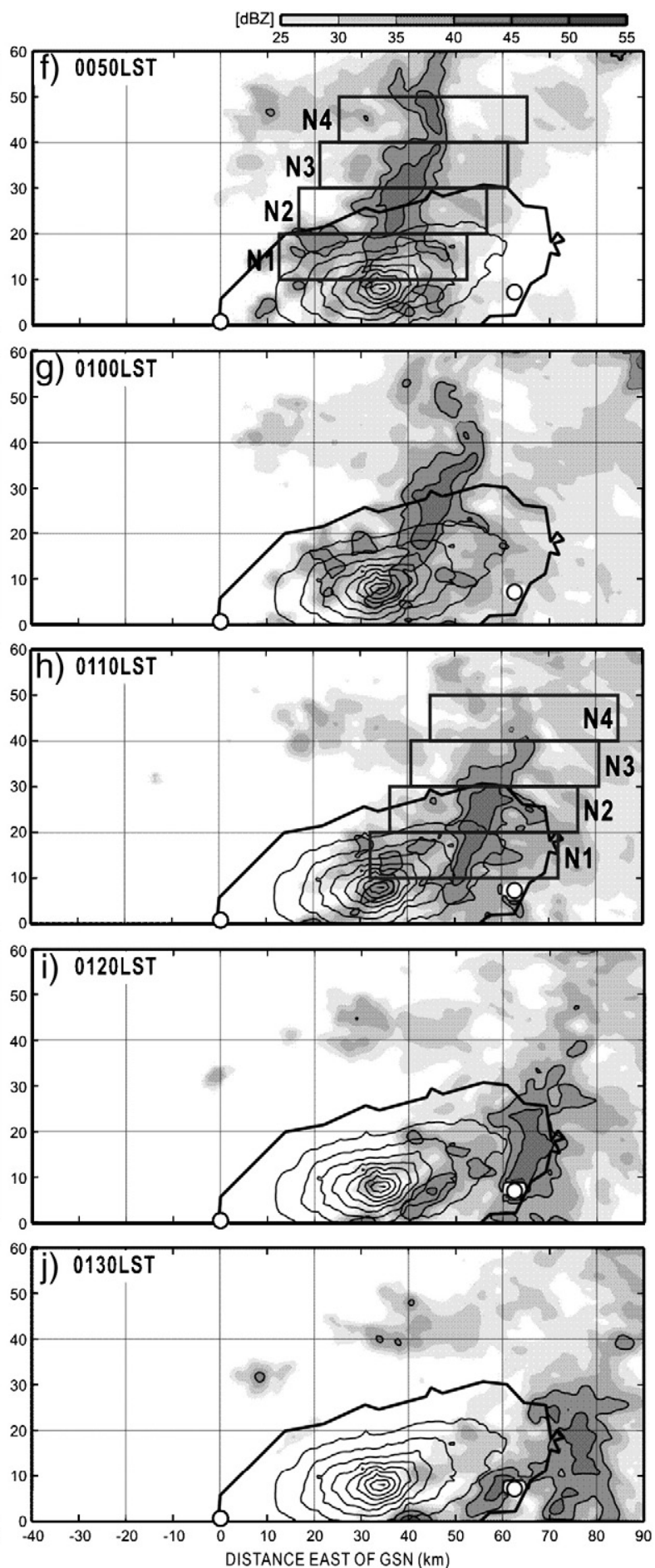

Fig. 5. Horizontal distributions of radar reflectivity at $2 \mathrm{~km}$ ASL for (a) 0000 LST, (b) 0010 LST, (c) 0020 LST, (d) 0030 LST, (e) 0040 LST, (f) 0050 LST, (g) 0100 LST, (h) 0110 LST, (i) 0120 LST, and (j) 0130 LST on 6 July 2007. The reflectivity contour interval is 5 dBZ starting from 40 dBZ. The darkest shading represents the convective region, with radar reflectivity larger than $45 \mathrm{dBZ}$. The four rectangles (N1, N2, N3, and N4) demark the regions used for the detailed analysis of the convective region shown in Figs. 6 and 17. The locations of the radar stations (GSN and SSN) are indicated by small open circles. Reflectivity is from the GSN radar alone for 0000-0050 LST and from the SSN radar alone for 0100-0130 LST.

$\left(\sim 10 \mathrm{~ms}^{-1}\right)$ while it moves through the area. The domain boundaries are depicted in Fig. 5b, d, f, and h. Fig. 6 shows the time variation of the horizontal area of the convective region at $2 \mathrm{~km}$ ASL for every 10 minutes between 2350 LST on 5 July and 0140 LST on 6 July 2007. To better understand the evolution of the system, the system passage can be divided 


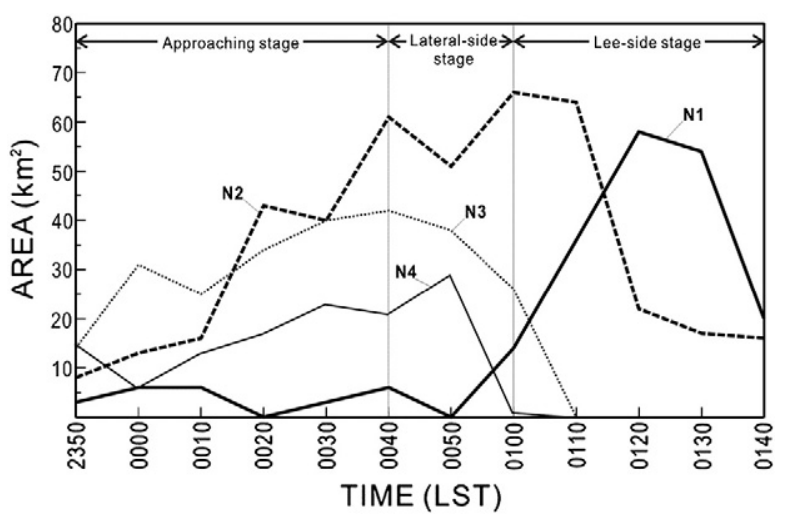

Fig. 6. Time variations of the horizontal area of the convective region (reflectivity greater than $45 \mathrm{dBZ}$ ) at $2 \mathrm{~km}$ ASL within the $\mathbf{N 1}$ (thick solid line), $\mathbf{N 2}$ (thick dashed line), N3 (thin dotted line), and N4 (thin solid line) analysis domains. The boundaries of the analysis domains are shown in Fig. 5.

into three stages based on its location relative to the mountain: approaching stage (0000-0030 LST), lateral-side stage (0040-0050 LST), and lee-side stage (0100-0130 LST). The area of the convective region in the $\mathbf{N 1}$ domain was less than $10 \mathrm{~km}^{2}$ during the approaching and lateral-side stages (Fig. 6, thick solid line). This area expanded to approximately $60 \mathrm{~km}^{2}$ during the lee-side stage, when the convective region moved to the eastern part of Jeju Island, but decreased again after 0130 LST. The area of the convective region in the $\mathbf{N 2}$ domain consistently enlarged $\left(\sim 60 \mathrm{~km}^{2}\right)$ during the approaching and lateral-side stages, with a maximum area of approximately $65 \mathrm{~km}^{2}$ at 0100 LST (Fig. 6, thick dashed line). This area decreased sharply during the lee-side stage, to approximately $20 \mathrm{~km}^{2}$. The area of the convective region in the $\mathbf{N} \mathbf{3}$ domain expanded gradually during the approaching stage to a maximum of approximately $40 \mathrm{~km}^{2}$, before decreasing gently during the lateral-side stage (Fig. 6, thin dotted line). Similarly, the convective region in the $\mathbf{N} \mathbf{4}$ domain expanded gradually during the approaching stage to a maximum of approximately $30 \mathrm{~km}^{2}$ before decreasing sharply during the lateral-side stage (Fig. 6, thin solid line). During the lee-side stage, the areas of the convective regions within $\mathbf{N} 3$ and $\mathbf{N 4}$ were negligible.

The convective region within this elongated precipitation system evolved differently in each analysis domain (N1-N4) as the system developed relative to the island (approaching stage, lateral-side stage, and lee-side stage). In particular, the convective region in N2 underwent a sharp enhancement near the northwestern coast of the island during the approaching stage. During the lee-side stage, a similar sharp enhancement of the convective region in $\mathbf{N 1}$ occurred on the eastern slope of the island. By contrast, the convective regions in N3 and N4 expanded gradually during the approaching stage, and then dissipated during the lateral-side and lee-side stages after passing around northern part of the island. To reveal the enhancement mechanisms of this precipitation system, the detailed structures and evolutions of the significantly enhanced convective regions in $\mathbf{N 2}$ during the approaching stage and in N1 during the lee-side stage are examined in detail and contrasted with the structure and evolutions of the less-enhanced convective regions in N3 and N4. This analysis is accomplished using 3-dimensional reflectivity and wind structure from dual-Doppler radar data.

\section{Three-dimensional structure of the convective region}

The detailed structure of the evolution of the convective region is analyzed for each of the three stages of precipitation system development using dual-Doppler radar data.

\subsection{Approaching stage (0000-0030 LST)}

The horizontal evolution of the convective region between 0000 and 0030 LST is shown as a sequence of the horizontal distribution of reflectivity (contouring from 35 $\mathrm{dBZ}$ with $5 \mathrm{dBZ}$ intervals and shading between 40 and 45 $\mathrm{dBZ}$ ) at $2 \mathrm{~km}$ ASL in Fig. 7a-d. Each panel of Fig. 7 shows an area of $40 \mathrm{~km} \times 45 \mathrm{~km}$, the location of which is shifted approximately $10 \mathrm{~km}$ eastward every 10 minutes. The horizontal axis indicates the distance east of the GSN radar, and the vertical axis indicates the distance north of the GSN radar. As shown in Fig. 6, the convective region strengthened during the approaching stage in all four regions (N1-N4). Between 0010 and 0030 LST (Fig. 7b-d), as the convective region strengthened, relatively strong westerly winds $\left(18 \mathrm{~ms}^{-1}\right)$ prevailed at the western side and relatively weak southwesterly winds $\left(9 \mathrm{~ms}^{-1}\right)$ prevailed at the eastern side of the elongated precipitation system at $2 \mathrm{~km}$ ASL (Fig. 7f-h). Simultaneously, an elongated updraft region (oriented southwest-to-northeast, dark shading for updraft larger than $1.5 \mathrm{~ms}^{-1}$ ) became obvious on the west side of the precipitation system (Fig. 7j-k). At 0010 LST (Fig. 7f), southwesterly winds $\left(13 \mathrm{~ms}^{-1}\right)$ prevailed in the southern part of the system, from $7 \mathrm{~km}$ west to $3 \mathrm{~km}$ east and 5 to $12 \mathrm{~km}$ north of GSN. As the system approached the northwestern coast of the island at 0020 LST (Fig. 7g), these southwesterly winds accelerated to approximately $20 \mathrm{~ms}^{-1}$. This acceleration induced an updraft region between the southern part of the precipitation system and the northwestern coast of the island, around $5 \mathrm{~km}$ east and $15 \mathrm{~km}$ north of GSN (Fig. 7k). At 0030 LST, this updraft region was located $15 \mathrm{~km}$ east and $15 \mathrm{~km}$ north of GSN (Fig. 7l). Relatively weak southwesterly winds $\left(12 \mathrm{~ms}^{-1}\right)$ appeared at the northwestern side of the island at 0030 LST (Fig. 7h), while the precipitation system continued to be characterized by relatively strong westerly winds on its western side and relatively weak southwesterly winds on its eastern side. The winds associated with the precipitation system were of similar direction at $4 \mathrm{~km}$ ASL between 0010 and 0030 LST (Fig. 7n-p), with westerly winds $\left(13 \mathrm{~ms}^{-1}\right)$ on the western side and southwesterly winds $\left(11 \mathrm{~ms}^{-1}\right)$ on the eastern side. Westerly winds $\left(13 \mathrm{~ms}^{-1}\right)$ also prevailed at $4 \mathrm{~km} \mathrm{ASL}$ to the south of the system during 0010-0020 LST (Fig. 7n-0), in contrast to the accelerated southwesterlies at $2 \mathrm{~km}$ ASL (Fig. $7 \mathrm{f}-\mathrm{g}$ ). This configuration persisted over the northwestern side of the island through 0030 LST (Fig. 7p), with westerly winds $\left(13 \mathrm{~ms}^{-1}\right)$ at $4 \mathrm{~km}$ ASL overlying weak southwesterly winds $\left(12 \mathrm{~ms}^{-1}\right)$ at $2 \mathrm{~km}$ ASL (Fig. 7h).

Several vertical cross-sections have been selected from the regions depicted in Fig. $7 c-d$ to illustrate the vertical structure of the updraft region and accelerated southwesterly winds that were generated off the northwestern coast of the 


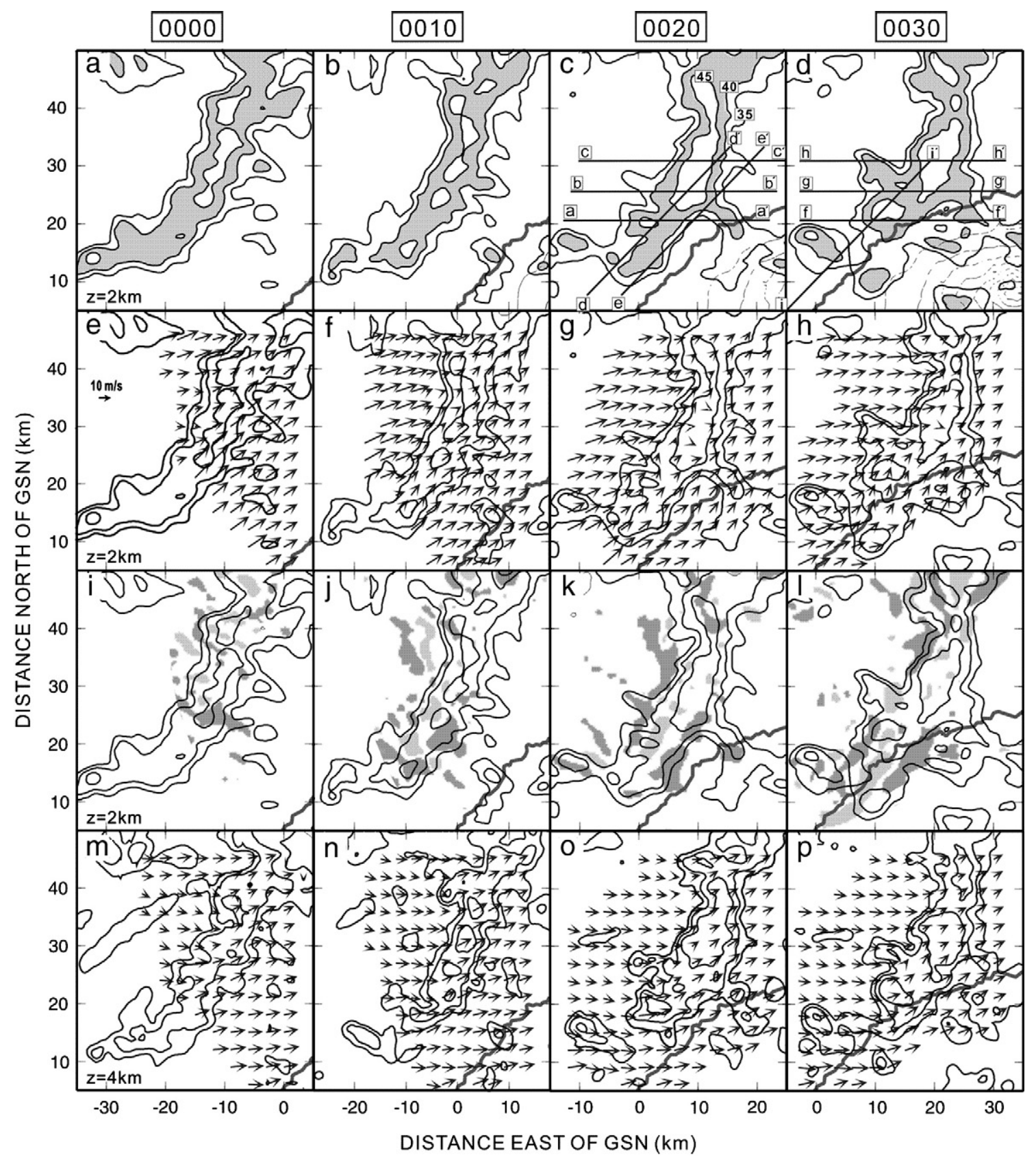

Fig. 7. Horizontal distributions of reflectivity and system-relative wind fields during the approaching stage (0000-0030 LST). The first row (a)-(d) shows the radar-echo intensity at $2 \mathrm{~km}$ ASL. The reflectivity contours are drawn every $5 \mathrm{dBZ}$ from $35 \mathrm{dBZ}$. Areas with reflectivity between 40 and $45 \mathrm{dBZ}$ are shaded. The second row (e)-(h) and the fourth row (m)-(p) show horizontal wind vectors and reflectivity (contours as in the first row) at $2 \mathrm{~km}$ and $4 \mathrm{~km}$ ASL, respectively. The third row (i)-(l) shows vertical air velocity (shading) at $2 \mathrm{~km}$ ASL. Regions of updraft larger than $1.5 \mathrm{~ms}^{-1}$ are shown as dark shading and regions of downdraft less than $-1.5 \mathrm{~m} \mathrm{~s}^{-1}$ are shown as light shading. The thick contour line in each panel represents the coastline of Jeju Island. The thin broken lines in (b)-(d) show the topography of Jeju Island (contour interval $200 \mathrm{~m}$ ). The locations of the vertical cross-sections shown in Fig. 8 are indicated in (c), and the locations of those shown in Fig. 9 are indicated in (d).

island, to the south of the precipitation system. Fig. 8 shows vertical cross-sections of radar reflectivity (contouring every $5 \mathrm{dBZ}$ from $35 \mathrm{dBZ}$ with thick lines from $45 \mathrm{dBZ}$ ) and wind along the transect lines $a-a^{\prime}, b-b^{\prime}, c-c^{\prime}, d-d^{\prime}$, and e- $e^{\prime}$ at 0020 LST. The transect lines $a-a^{\prime}, b-b^{\prime}$, and $c-c^{\prime}$ were selected from around the $\mathbf{N 2}$ analysis domain because they are oriented parallel to the horizontal axis of Fig. 7c, near the N2 analysis domain. Along the $a-a^{\prime}$ transect, the convective region had a maximum height of $6.5 \mathrm{~km}$ ASL and a maximum width of $6 \mathrm{~km}$ (Fig. 8a). A region of paired updrafts (dark shading) and the downdrafts (light shading) was located near this convective region, extending from 1 to $6 \mathrm{~km} \mathrm{ASL}$ at $10-20 \mathrm{~km}$. The thick downward arrow on the horizontal axis of Fig. 8a indicates the Jeju Island coastline. Another 

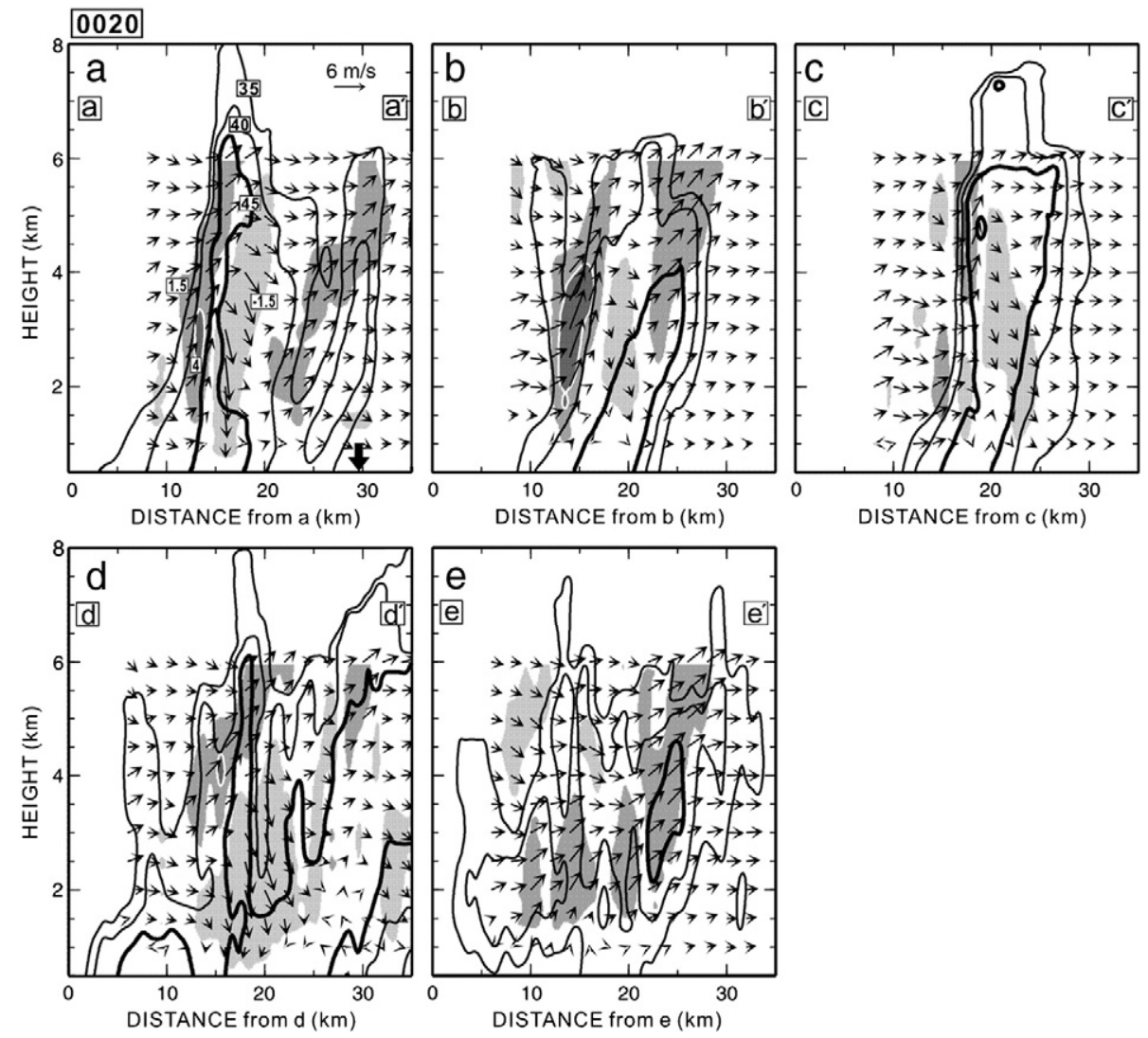

Fig. 8. Vertical cross-sections of reflectivity and system-relative wind fields at 0020 LST. The locations of the transect lines are shown in Fig. 7c. Transects a-a' to c- $c^{\prime}$ are oriented parallel to the horizontal axis of Fig. 7c. Transects $\mathrm{d}^{-\mathrm{d}^{\prime}}$ and $\mathrm{e}-\mathrm{e}^{\prime}$ are oriented parallel to the prevailing southwesterly wind. Regions of updrafts in excess of $1.5 \mathrm{~ms}^{-1}$ are shown as dark shading and regions of downdraft less than $-1.5 \mathrm{~ms}^{-1}$ are shown as light shading. The regions of intense updrafts (greater than $4 \mathrm{~ms}^{-1}$ ) are indicated by the darkest shading bounded by white contours. Thin contours indicate radar reflectivity from a minimum of $35 \mathrm{dBZ}$, with a contour interval of $5 \mathrm{dBZ}$. Thick contours indicate reflectivity in excess of $45 \mathrm{dBZ}$, with a contour interval of $5 \mathrm{dBZ}$. A thick downward arrow along the horizontal axis in (a) indicates the location of the Jeju Island coastline.

updraft region is apparent to the east of this coastline, between the convective region and the island. This updraft region extended from 1.5 to $6 \mathrm{~km}$ ASL at $20-30 \mathrm{~km}$, with reflectivity in excess of $35 \mathrm{dBZ}$ up to $6 \mathrm{~km}$ ASL. Along the b-b' transect (Fig. 8b), located $5 \mathrm{~km}$ north of the a-a' transect, the convective region is tilted in the vertical from lower-west to upper-east $(15-25 \mathrm{~km})$. This vertically tilted convective region extended from the surface to $4 \mathrm{~km}$ ASL with a maximum width of $7 \mathrm{~km}$. A region of paired updrafts and downdrafts (dark and light shadings) is apparent along this transect at $10-20 \mathrm{~km}$, including an area of intense updrafts (stronger than $4 \mathrm{~ms}^{-1}$; depicted by the darkest shading) between 2 and $4 \mathrm{~km}$ ASL. The updrafts located in the rear of the elongated precipitation system $(10-17 \mathrm{~km})$ from 1 to $6 \mathrm{~km}$ ASL, and the reflectivity of $35 \mathrm{dBZ}$ increased to $6 \mathrm{~km}$ ASL $(15-20 \mathrm{~km})$. In $14-20 \mathrm{~km}$, the relatively short convective region was identified to be $3 \mathrm{~km}$ ASL from surface, adjacent to the downdrafts below $4 \mathrm{~km} \mathrm{ASL}$. To the east side of the downdrafts, an additional updraft region $(20-30 \mathrm{~km}$ in Fig. $8 \mathrm{~b})$ can be identified above $3 \mathrm{~km}$ ASL, with the extended convective region up to $4 \mathrm{~km}$ ASL. Along the $\mathrm{c}-\mathrm{c}^{\prime}$ transect (Fig. $8 \mathrm{c}$ ), the convective region extended from the surface to $6 \mathrm{~km}$ ASL with a maximum width of $10 \mathrm{~km}$. The updraft region can be found adjacent to the convective region, from 1.5 to $6 \mathrm{~km}$ ASL, and the downdraft region can be found below $5 \mathrm{~km}$ ASL to the east of the updraft region. The additional updraft region identified to the east of the downdraft along the $a-a^{\prime}$ and $b-b^{\prime}$ transects (Fig. 8a-b) is not apparent along the $\mathrm{c}-\mathrm{c}^{\prime}$ transect (Fig. 8c). The updrafts between the convective region and the island were generated locally by the convergence of the strong westerly wind and the enhanced southwesterly wind.

The vertical transects $\mathrm{d}-\mathrm{d}^{\prime}$ and $\mathrm{e}-\mathrm{e}^{\prime}$ (Fig. 8d-e) are oriented parallel to the enhanced southwesterly wind. As shown in Fig. $7 c$, the $d-d^{\prime}$ transect is located at the center of the southern edge of the precipitation system, while the e- $\mathrm{e}^{\prime}$ transect is located off the northwestern shore of the island. Along the $\mathrm{d}-\mathrm{d}$ ' transect (Fig. 8d), the convective region extended from the surface to $6 \mathrm{~km}$ ASL over a relatively wide horizontal range $(5-35 \mathrm{~km})$. An updraft region was located adjacent to the convective region $(10-20 \mathrm{~km})$ from 3 to $6 \mathrm{~km}$ ASL, with a downdraft region below. The convective region was relatively small along the e- $\mathrm{e}^{\prime}$ transect (Fig. 8e), in the region of accelerated southwesterly winds (Fig. $7 \mathrm{~g}$ ) and updraft region (Fig. 7k), extending only from 2 to $4.5 \mathrm{~km}$ ASL. A relatively wide updraft region is apparent along this 
transect at $10-28 \mathrm{~km}$. This updraft region tilted from lowersouthwest to upper-northeast, and extended from 1.5 to $6 \mathrm{~km}$ ASL.

Fig. 9 shows vertical cross-sections of reflectivity and wind at 0030 LST along the $\mathrm{f}-\mathrm{f}^{\prime}, \mathrm{g}-\mathrm{g}^{\prime}, \mathrm{h}-\mathrm{h}^{\prime}$, and $\mathrm{i}-\mathrm{i}^{\prime}$ transect lines (Fig. $7 d$ ). The $f-f^{\prime}, g-g^{\prime}$, and $h-h^{\prime}$ transect lines are oriented parallel to the horizontal axis of Fig. $7 d$ and spaced at $5 \mathrm{~km}$ intervals. Along the $\mathrm{f}-\mathrm{f}^{\prime}$ transect (Fig. 9f), the convective region extended from 1.5 to $6 \mathrm{~km}$ ASL with a maximum width of $6 \mathrm{~km}$. A related updraft region was located to the west of the convective region. This updraft region extended from 1 to $6 \mathrm{~km}$ ASL, and included areas of intense updrafts (stronger than $4 \mathrm{~ms}^{-1}$; depicted by the darkest shading) above $2 \mathrm{~km}$ ASL. Another updraft region that extended from 1.5 to $6 \mathrm{~km}$ ASL is apparent to the east of the Jeju Island coastline (indicated by thick downward arrow), in a similar location (east of the downdrafts) to the additional updraft region identified along the $a-a^{\prime}$ transect (Fig. 8a). Reflectivity in excess of $40 \mathrm{dBZ}$ extended to $5 \mathrm{~km}$ ASL in this updraft region. Along the $\mathrm{g}-\mathrm{g}^{\prime}$ transect (Fig. 9g), the convective region extended from 1 to $5.5 \mathrm{~km}$ ASL over the $17-25 \mathrm{~km}$ range, with a maximum width of $4 \mathrm{~km}$. A relatively wide updraft region ( $17 \mathrm{~km}$ maximum width) can be identified above $2.5 \mathrm{~km}$ ASL adjacent to the convective region, with intense updrafts at $3-4 \mathrm{~km}$ ASL. Along the $\mathrm{h}-\mathrm{h}^{\prime}$ transect (Fig. 9h), the convective region extended from 1.5 to $7 \mathrm{~km}$ ASL. A relatively narrow updraft region was located above $3 \mathrm{~km}$ ASL to the west of the convective region, in the range of $20-25 \mathrm{~km}$. Downdrafts were predominant below $4 \mathrm{~km}$ ASL inside of the convective region.

The vertical cross-section $\mathrm{i}-\mathrm{i}^{\prime}$ is oriented parallel to the southwesterly wind as shown in Fig. $7 d$, with the same cross-section angle as the $\mathrm{d}-\mathrm{d}^{\prime}$ and $\mathrm{e}-\mathrm{e}^{\prime}$ transects (Fig. 7c). The updraft region along the $\mathrm{i}-\mathrm{i}^{\prime}$ transect (Fig. 9i), was relatively wider $(20 \mathrm{~km})$ including intensive updrafts, than those identified along the $\mathrm{d}-\mathrm{d}^{\prime}$ and $\mathrm{e}-\mathrm{e}^{\prime}$ transects (Fig. 8d-e). This updraft region extended from 1 to $6 \mathrm{~km}$ ASL over the $15-20 \mathrm{~km}$ range (Fig. 9i), with intense updrafts above $2 \mathrm{~km}$ ASL. A relatively tall convective region (1.5 to $6 \mathrm{~km}$ ASL) was located to the northeast of the updraft region at $22-27 \mathrm{~km}$, and included another region of intense updrafts above $4.5 \mathrm{~km}$ ASL.

\subsection{Lateral-side stage (0040-0050 LST)}

The convective region near the northern coast of the island (N2) retained its area during the lateral-side stage, while the areas of the offshore convective regions (N3 and N4) gradually dissipated (see Fig. 6). Detailed horizontal distributions of reflectivity and wind during 0040-0050 LST are shown in Fig. 10.

The consistency of the area of the retained convective region in $\mathbf{N 2}$ (Figs. 6 and 10a-b) can be explained by convergence of westerly winds $\left(8 \mathrm{~ms}^{-1}\right)$ at the western edge of the convective region and southwesterly winds $\left(10 \mathrm{~ms}^{-1}\right)$ over the northwestern slope of the island. At $2 \mathrm{~km} \mathrm{ASL}$, this convergence is consistently located $10-30 \mathrm{~km}$ east and $10-25 \mathrm{~km}$ north of GSN (Fig. 10c-d). This horizontal wind distribution induced an updraft region over the northern part of the island (Fig. 10e-f). At $4 \mathrm{~km}$ ASL (Fig. 10g-h), the winds over the northwestern slope of the island were predominantly westerly. The convective regions in N3 and N4 gradually dissipated off the northern shore of the island (Figs. 6 and 10ab). Westerly $\left(15 \mathrm{~ms}^{-1}\right)$ and southwesterly $\left(10 \mathrm{~ms}^{-1}\right)$ winds appeared at the western and eastern edges of the convective region, respectively (Fig. 10c-d), and the area of the updraft region at $2 \mathrm{~km}$ ASL gradually decreased (Fig. 10e-f). At 0050 LST, the winds in the convective region were predominantly westerly (15 $\mathrm{ms}^{-1}$; Fig. 10d).

Several vertical cross-sections are used to examine the convective region over the northern part of the island during the lateral-side stage in further detail. The locations of the transect lines are indicated in Fig. 10a-b. Fig. 11 shows vertical cross-sections of reflectivity and wind along the $a-a^{\prime}$, b- $b^{\prime}, c-c^{\prime}, d-d^{\prime}$, and e-e transect lines at 0040 LST. The $a-a^{\prime}$ to $\mathrm{d}-\mathrm{d}^{\prime}$ transects are oriented parallel to the Jeju Island coastline and spaced at $5 \mathrm{~km}$ intervals from the northern slope of the island to the sea off the northern shore. No convective region is discernable along the a-a' transect (Fig. 11a), although an updraft region that extended from 1 to $6 \mathrm{~km}$ ASL is apparent

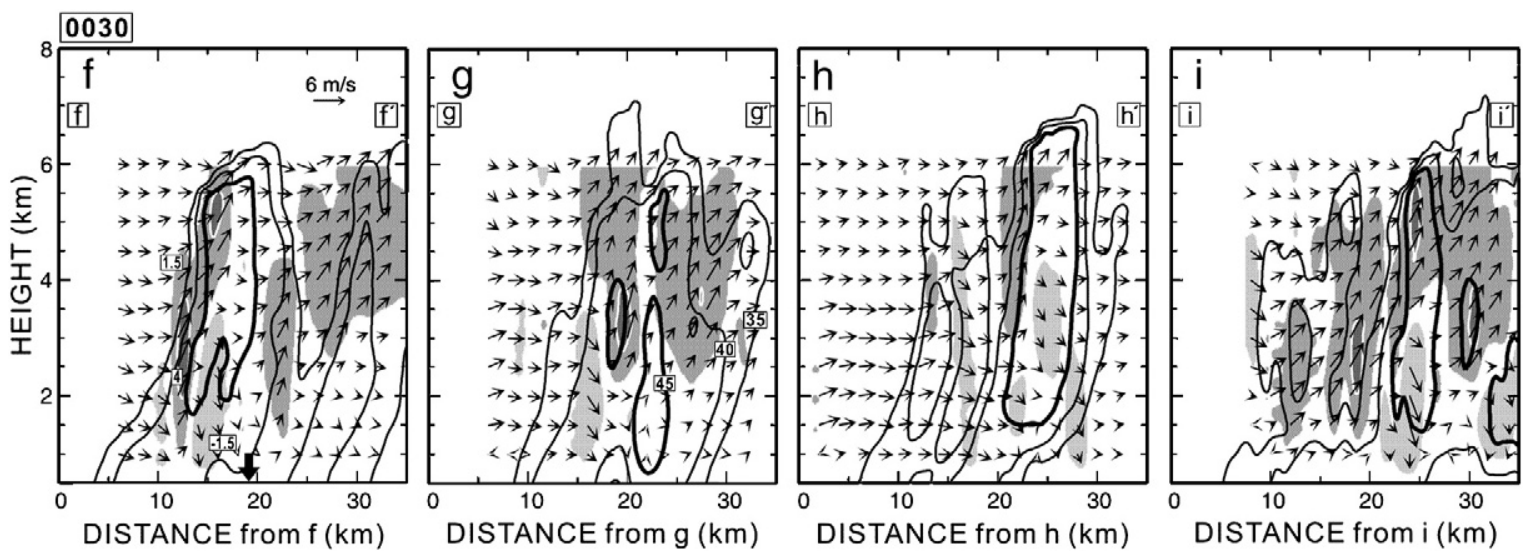

Fig. 9. Vertical cross-sections of reflectivity and system-relative wind fields at 0030 LST. The locations of the transect lines are shown in Fig. $7 d$. Transects $f-f^{\prime}$ to $\mathrm{h}-\mathrm{h}^{\prime}$ are oriented parallel to the horizontal axis of Fig. $7 \mathrm{~d}$. Transect $\mathrm{i}-\mathrm{i}^{\prime}$ is oriented parallel to the southwesterly wind. The shaded regions and contours are as in Fig. 8. A thick downward arrow along the horizontal axis in (f) shows the location of the Jeju Island coastline. 


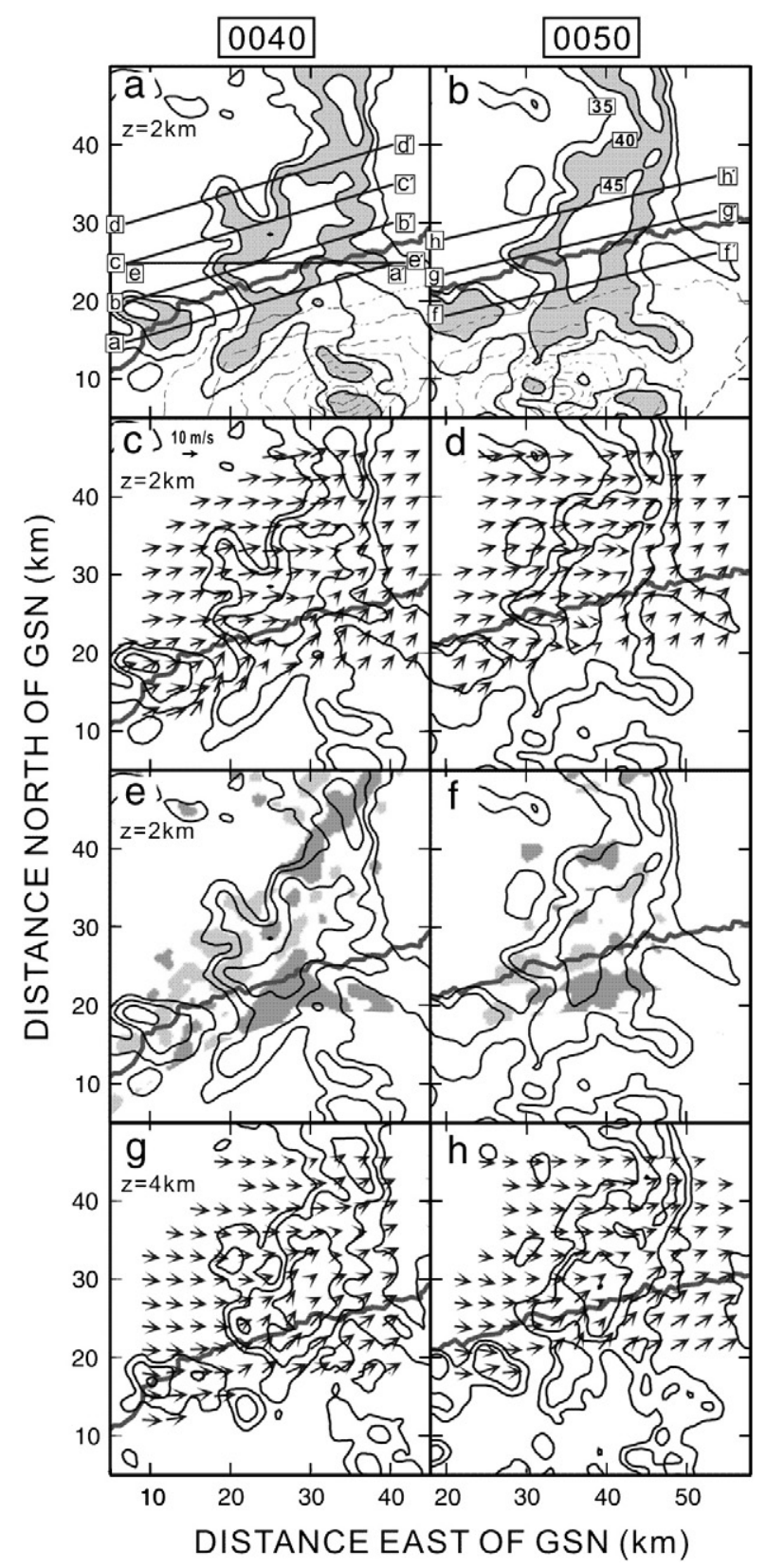

Fig. 10. Horizontal distributions of reflectivity and system-relative wind fields during the lateral-side stage (0040-0050 LST). The shaded regions and contours are as in Fig. 7. The locations of the vertical cross-sections shown in Fig. 11 are indicated in (a) and the locations of those shown in Fig. 12 are indicated in (b).

over a relatively wide horizontal range $(10-35 \mathrm{~km})$. Intense updrafts (stronger than $4 \mathrm{~ms}^{-1}$ ) occurred between 2 and $5 \mathrm{~km}$ ASL at $16-19 \mathrm{~km}$, over the northwestern slope of the island where southwesterly winds were predominant (Fig. 10c). At the northeast of the intense updraft region $(19-24 \mathrm{~km})$, the height of $40 \mathrm{dBZ}$ was $6 \mathrm{~km}$ ASL. These southwesterly winds converged with the predominant westerly winds along the b-b' transect (Figs. 10c and 11b). Along this transect, the convective region extended from the surface to $7 \mathrm{~km}$ ASL with a maximum width of $14 \mathrm{~km}$. A region of intense updraft region was located in the $17-23 \mathrm{~km}$ range (Fig. $11 \mathrm{~b}$ ). A relatively tall convective region (up to $7 \mathrm{~km} \mathrm{ASL}$ ) was located near the northeastern edge of this intense updraft region. Updrafts along the $c-c^{\prime}$ transect (Fig. 11c) were relatively weak. The convective region along this transect had a maximum height of $6 \mathrm{~km}$ ASL and a maximum width of $7 \mathrm{~km}$. Along the $\mathrm{d}^{-\mathrm{d}^{\prime}}$ transect, off the northern shore of the island (Fig. 11d), the updraft region was even weaker and convective region only reached to $3.5 \mathrm{~km}$ ASL.

The $\mathrm{e}-\mathrm{e}^{\prime}$ transect line is located near the coastline and oriented parallel to the direction of precipitation system movement. Along the $\mathrm{e}-\mathrm{e}^{\prime}$ transect (Fig. 11e), the convective region extended from the surface to $5.5 \mathrm{~km}$ ASL with a maximum width of $8.5 \mathrm{~km}$, and was slightly tilted from 

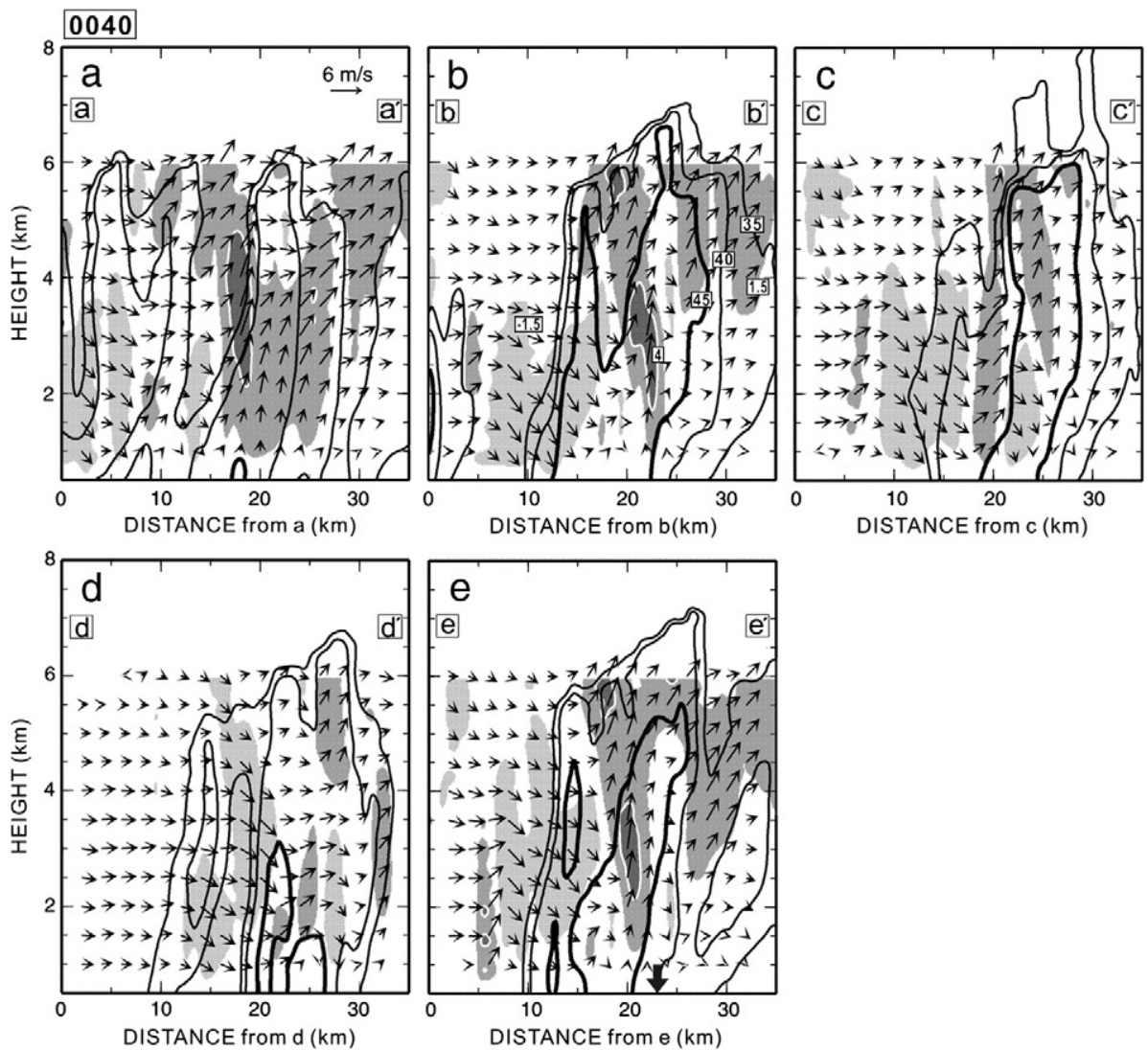

Fig. 11. Vertical cross-sections of reflectivity and system-relative winds at 0040 LST. Locations of the transect lines are shown in Fig. 10a. Transects a-a', b-b', c-c', and $\mathrm{d}-\mathrm{d}^{\prime}$ are oriented parallel to the Jeju Island coastline. Transect e- $\mathrm{e}^{\prime}$ is oriented parallel to the horizontal axis of Fig. 10a. The shaded regions and contours are as in Fig. 8. A thick downward arrow on the horizontal axis of (e) indicates the location of the coastline.

lower-west to upper-east. The Jeju Island coastline is indicated by a thick downward arrow on the horizontal axis of Fig. 11e. In the e-e' transect, the westerly and southwesterly winds converged in the offshore area between the coastline and the point located $15 \mathrm{~km}$ from point 'e' in Fig. 11e, inducing a region of intense updrafts at $2-4 \mathrm{~km}$ ASL. The convective region east of these intense updrafts extended to $5.5 \mathrm{~km}$ ASL. Reflectivity in this convective region exceeded $35 \mathrm{dBZ}$ up to $7 \mathrm{~km}$ ASL. Downdrafts were predominant off the northwestern shore of the island, in the $7-15 \mathrm{~km}$ range (Fig. 11e).

Fig. 12 shows vertical cross-sections of reflectivity and wind along the $\mathrm{f}-\mathrm{f}^{\prime}, \mathrm{g}-\mathrm{g}^{\prime}$, and $\mathrm{h}-\mathrm{h}^{\prime}$ transect lines at 0050 LST (Fig. 10b). The $\mathrm{f}-\mathrm{f}^{\prime}$ to $\mathrm{h}-\mathrm{h}^{\prime}$ transects in Fig. 12 are oriented parallel to the coastline of the island and spaced at $5 \mathrm{~km}$ intervals from the northern slope of the island to the sea off the northern shore. Along the $\mathrm{f}-\mathrm{f}^{\prime}$ transect (Fig. 12f), where southwesterly winds were predominant (Fig. 10d), the convective region extended from 1 to $4.5 \mathrm{~km}$ ASL with a maximum width of $5 \mathrm{~km}$. A related updraft region is apparent at $10-25 \mathrm{~km}$, with intense updrafts from 2 to $6 \mathrm{~km}$ ASL (Fig. 12f). By contrast, the convective regions along the $\mathrm{g}-\mathrm{g}^{\prime}$ and $\mathrm{h}-\mathrm{h}^{\prime}$ transects $\left(5\right.$ and $10 \mathrm{~km}$ north of the $\mathrm{f}-\mathrm{f}^{\prime}$ transect, respectively) contained enlarged downdraft regions and relatively small updraft regions (Fig. 12g-h).
On the basis of Figs. 11 and 12, the intense updraft region over the northern slope of the island was induced locally by convergence of the predominant westerly and local southwesterly winds over the northwestern slope of the island. This convergence ensured that the convective region in $\mathbf{N 2}$ retained its area as it passed over the northern slope of the island.

\subsection{Lee-side stage (0100-0130 LST)}

During the lee-side stage, the area of the convective region in $\mathbf{N 1}$ expanded significantly, whereas that of the convective region in N2 was reduced (see Fig. 6). Fig. 13 shows the detailed horizontal evolutions of reflectivity and wind in the vicinity of the convective region. At 0100 LST (Fig. 13a), the precipitation system is located over the northeastern part of the island and moving eastward. The area of the convective region at $2 \mathrm{~km}$ ASL in $\mathbf{N} 2$ was roughly unchanged from that in the lateral-side stage at this point (Fig. 6). Westerly $\left(12 \mathrm{~ms}^{-1}\right)$ and southwesterly $\left(13 \mathrm{~ms}^{-1}\right)$ winds were observed approximately $35 \mathrm{~km}$ east and $25 \mathrm{~km}$ north of GSN (Fig. 13e). The convergence of these winds induced an updraft region on the western side of the convective region (Fig. 13h) in N2. Relatively strong southwesterly $\left(16 \mathrm{~ms}^{-1}\right)$ and weak westerly $\left(5 \mathrm{~ms}^{-1}\right)$ winds were 


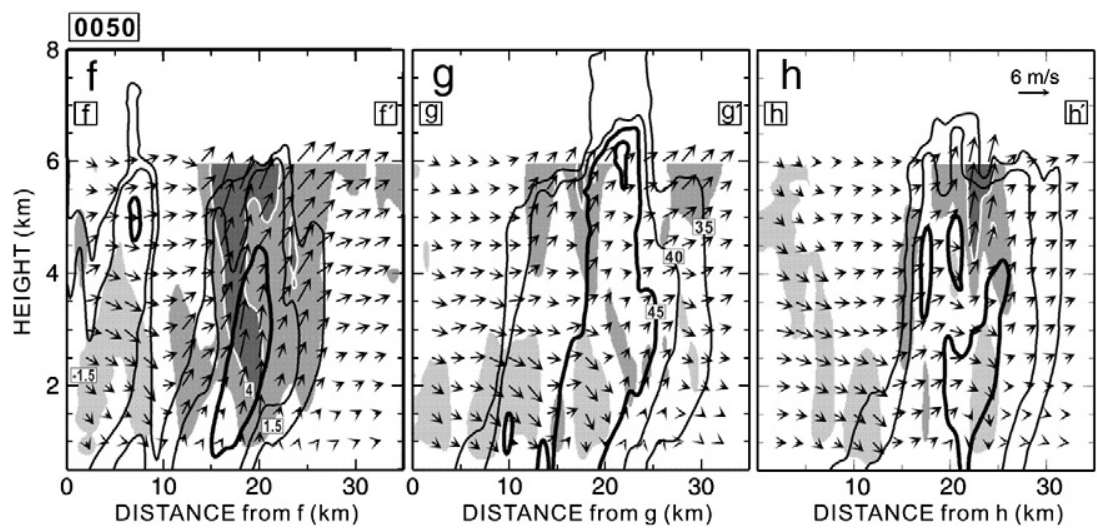

Fig. 12. Vertical cross-sections of reflectivity and system-relative wind fields at 0050 LST. The locations of the transect lines are indicated in Fig. $10 \mathrm{~b}$. Transects $\mathrm{f}-\mathrm{f}^{\prime}$, $\mathrm{g}-\mathrm{g}^{\prime}$, and $\mathrm{h}-\mathrm{h}^{\prime}$ are oriented parallel to the Jeju Island coastline. The shaded regions and contours are as in Fig. 8.

observed to the east of the convective region, $50 \mathrm{~km}$ east and $25 \mathrm{~km}$ north of GSN (Fig. 13e). Related updrafts occurred in a region $45-63 \mathrm{~km}$ east and $18-22 \mathrm{~km}$ north of GSN, ahead of the eastward-moving precipitation system (Fig. 13h). Strong southwesterly winds were also observed at $4 \mathrm{~km}$ ASL over the updraft region (Fig. 13k).

During 0100-0110 LST, the convective region moved with the predominant westerly wind to the eastern slope of the island, passing over the region of preexisting updrafts (Fig. 13a-b). At 0110 LST, the convective region in N1 (Fig. 5h) extended horizontally to the southwest (Fig. 13b). The updraft region at $2 \mathrm{~km}$ ASL was consistently located over the eastern part of the island adjacent to the convective region, $45-63 \mathrm{~km}$ east and $18-22 \mathrm{~km}$ north of GSN (Fig. 13i). Strong southwesterly $\left(20 \mathrm{~ms}^{-1}\right)$ and weak westerly $\left(6 \mathrm{~ms}^{-1}\right)$ winds were consistently observed in the vicinity of this updraft region (Fig. 13f). Off the northeastern shore of the island (N3 and N4), the steady westerly winds showed in $30-45 \mathrm{~km}$ north of GSN (Fig. 13f), where the relatively strong westerly and weak southwesterly were identified consistently from 0010 to 0050 LST at $2 \mathrm{~km}$ ASL (Fig. 7f-h, Fig. 7j-l, Fig. 10c-d, Fig. 10e-f). When the system located off the northeastern shore, farther from the island (Fig. 13a-b), the weak southwesterly wind was hardly discernible ahead of the system and the strong westerly wind occupied in the convective region. Simultaneously, the winds were dominant westerly (15 m s$\left.{ }^{-1}\right)$ at $4 \mathrm{~km} \mathrm{ASL} \mathrm{(Fig.} \mathrm{13k-l).} \mathrm{The} \mathrm{dissipated}$ southwesterly and the consequent steady westerly winds contributed to the further dissolution of the convective region off the northeastern shore of the island from 0110 LST (Fig. 13b).

The convective region in $\mathbf{N} \mathbf{1}$ retained its intensity as it approached the eastern coastal area of the island at 0120 LST, whereas the intensity of the convective region in $\mathbf{N 2}$ was relatively weak (Figs. 6 and 13c). During 0110-0120 LST, the convective region in $\mathbf{N 1}$ passed over the preexisting updraft region on the eastern slope of the island (see Fig. 13i), preserving the convective region as it entered the eastern coastal area of the island at 0120 LST. At this time, the winds over the eastern coast of the island were southwesterly at $10 \mathrm{~ms}^{-1}$ (Fig. 13g). This horizontal wind distribution weakened the updraft region (Fig. 13j). The winds at $4 \mathrm{~km}$ ASL over the eastern part of the island (Fig. $13 \mathrm{~m}$ ) were westerly and nearly homogeneous $\left(12 \mathrm{~ms}^{-1}\right)$. At $0130 \mathrm{LST}$, the convective region was located off the eastern shore of the island and was relatively reduced in size and intensity (Fig. 13d).

Several vertical cross-sections are used to examine the vertical structure of the convective region, the relatively strong southwesterly wind, and the preexisting updraft region in further detail. The locations of these transect lines are indicated in Fig. 13a-c. Fig. 14 shows the vertical sections of reflectivity and wind along the $a-a^{\prime}, b-b^{\prime}, c-c^{\prime}$, and d-d' transect lines at 0100 LST (Fig. 13a). Transects $a-a^{\prime}$ and $b-b^{\prime}$ are oriented perpendicular to the convective region and spaced $5 \mathrm{~km}$ apart. Along the $\mathrm{a}-\mathrm{a}^{\prime}$ transect (Fig. 14a), an upright convective region extended from 0.5 to $5.5 \mathrm{~km}$ ASL with a maximum width of $6 \mathrm{~km}$. Two updraft regions were located below $2.5 \mathrm{~km}$ ASL and above $4.5 \mathrm{~km}$ ASL at $13-18 \mathrm{~km}$ along the transect (Fig. 14a). The preexisting updraft region shown in Fig. 13h was located to the southeast of the convective region. This updraft region extended from 1 to $6 \mathrm{~km}$ ASL with a maximum width of $14 \mathrm{~km}$, and included an area of intense updrafts (stronger than $4 \mathrm{~ms}^{-1}$ ) above $2.5 \mathrm{~km}$ ASL. The maximum height of $40 \mathrm{dBZ}$ reflectivity exceeded $6 \mathrm{~km}$ ASL in the intense updraft region. At this time, the downdraft region was located on the northwestern side of the convective region $(0-15 \mathrm{~km})$. Along the $\mathrm{b}^{-\mathrm{b}^{\prime}}$ transect (Fig. 14b), $5 \mathrm{~km}$ north of the $\mathrm{a}-\mathrm{a}^{\prime}$ transect, the convective region extended from 1 to $5 \mathrm{~km}$ ASL with a maximum width of $8 \mathrm{~km}$. Downdrafts occurred below $5.5 \mathrm{~km}$ ASL, while updrafts occurred above $3 \mathrm{~km}$ ASL over the land area. The intense updraft region identified along a-a' (Fig. 14a) is not apparent along $\mathrm{b}-\mathrm{b}^{\prime}$.

The $\mathrm{c}-\mathrm{c}^{\prime}$ transect (Fig. 14c) is oriented parallel to the Jeju Island coastline (Fig. 13a). As with the $\mathrm{b}^{-\mathrm{b}^{\prime}}$ section, the convective region extended from 1 to $4.5 \mathrm{~km}$ ASL, with downdrafts prevalent below $5 \mathrm{~km}$ ASL. Along the $\mathrm{d}-\mathrm{d}^{\prime}$ transect (Fig. 14d), which is oriented parallel to the strong southwesterly wind and located over the eastern slope of the island (Fig. 13a), a concentrated narrow updraft region extended from 1 to $6 \mathrm{~km}$ ASL approximately $7-17 \mathrm{~km}$ along the transect. This updraft region contained an area of intense updrafts and a thin convective region ( $1.5 \mathrm{~km}$ wide) that extended from 2.5 to $3.5 \mathrm{~km}$ ASL. The updraft region was only localized ahead of the eastward-moving convective region over the eastern slope of the island at $1 \mathrm{~km}$ ASL and higher. 


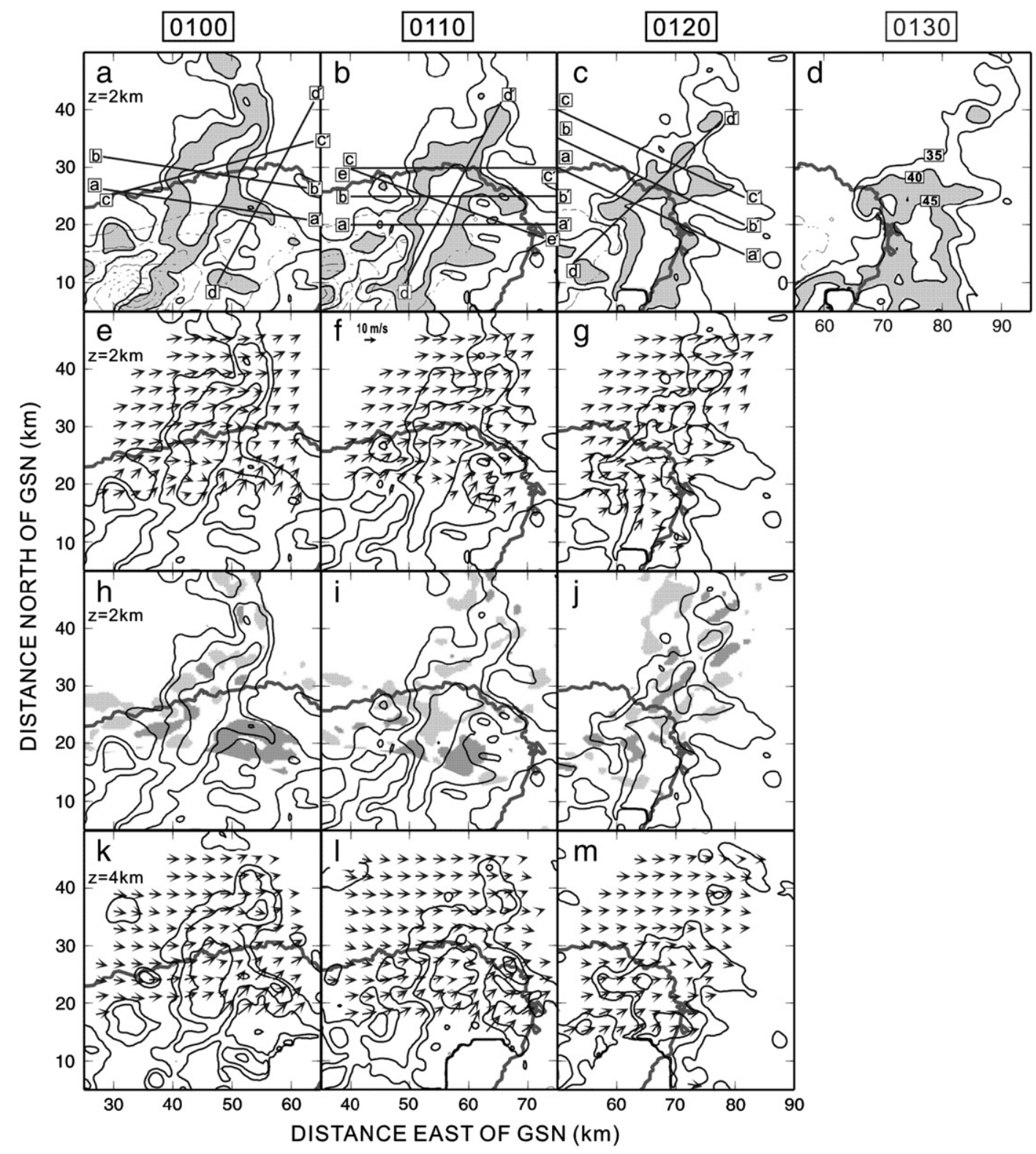

Fig. 13. Horizontal distributions of reflectivity and system-relative wind fields during the lee-side stage (0100-0130 LST). The shaded regions and contours are as in Fig. 7. The locations of the vertical cross-sections shown in Figs. 14, 15, and 16 are indicated in (a), (b), and (c), respectively.

Selected vertical distributions of reflectivity and wind fields at 0110 LST are presented in Fig. 15. The $a-a^{\prime}, b-b^{\prime}$, and $c-c^{\prime}$ transects are oriented parallel to the horizontal axis of Fig. $13 \mathrm{~b}$ and spaced at $5 \mathrm{~km}$ interval from the eastern slope to the northeastern coastal area of the island. Along the $a-a^{\prime}$ transect (Fig. 15a), the convective region was tilted from lower-west to upper-east, and extended from the surface to $7.5 \mathrm{~km}$ ASL at $10-20 \mathrm{~km}$ along the transect. Updrafts were predominant within the convective region, including two regions of intense updrafts (the darkest shading). One intense updraft region was located above $2 \mathrm{~km}$ ASL, at the west side of the convective region near $8-15 \mathrm{~km}$. Another intense updraft region was located above $3.5 \mathrm{~km}$ ASL near $15-25 \mathrm{~km}$, and included a relatively tall convective region that extended up to $7.5 \mathrm{~km}$ ASL. Along the b-b' transect (Fig. 15b), $5 \mathrm{~km}$ north of a-a ', the convective region was dominated by downdrafts. A narrow updraft region was located at $8-10 \mathrm{~km}$ along the transect with a vertical extent from 1 to $3.5 \mathrm{~km}$ ASL. To the east of this narrow updraft region, the convective region extended from the surface to $6 \mathrm{~km}$ ASL with a maximum width of $7 \mathrm{~km}$. To the east of this convective region, another updraft region was located at $20-32 \mathrm{~km}$ above $2 \mathrm{~km}$ ASL, including a short convective region between 2 and $4 \mathrm{~km}$ ASL. The maximum height of $40 \mathrm{dBZ}$ reflectivity in this updraft region was $5.5 \mathrm{~km}$ ASL. Along the $c-c^{\prime}$ transect (Fig. $15 c$ ), $5 \mathrm{~km}$ north of $b-b^{\prime}$, the convective region was even further diminished. This convective 


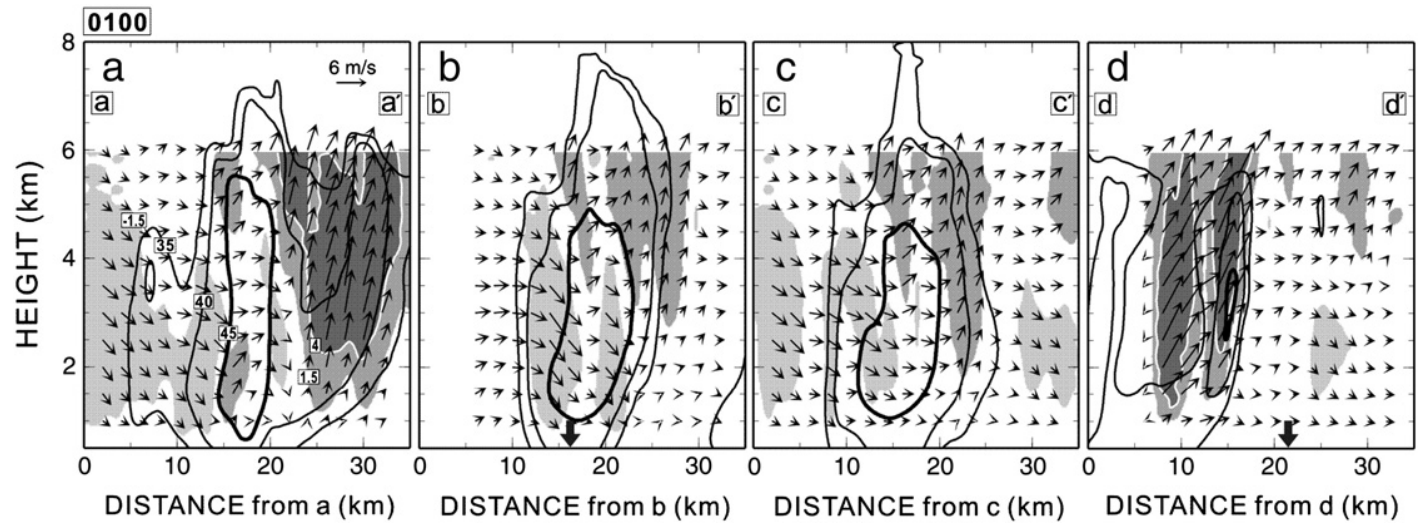

Fig. 14. Vertical cross-sections of reflectivity and system-relative wind fields at 0100 LST. The locations of the transect lines are shown in Fig. $13 a$. Transects a-a' and $b-b^{\prime}$ are oriented perpendicular to the precipitation system. Transect $c-c^{\prime}$ is oriented parallel to the Jeju Island coastline. Transect $d-d^{\prime}$ is oriented parallel to the southwesterly wind. The shaded regions and contours are as in Fig. 8. Thick downward arrows on the horizontal axes in (b) and (d) indicate the locations of the coastline along these transects.

region extended from 2 to $4 \mathrm{~km}$ ASL with maximum width of $4 \mathrm{~km}$, and was dominated by downdrafts. The updraft region was very small, and is barely discernable in Fig. 15c.

The $\mathrm{d}-\mathrm{d}^{\prime}$ transect (Fig. 15d) is oriented parallel to the strong southwesterly wind and passes through the center of the convective region. The convective region was horizontally extensive along this transect, with a maximum width of $20 \mathrm{~km}$. A relatively short convective region ( 1 to $3 \mathrm{~km} \mathrm{ASL}$ ) was located at $0-10 \mathrm{~km}$, over the eastern slope of the island. Updrafts were prevalent in this region above $2 \mathrm{~km} \mathrm{ASL}$, including an area of intense updrafts between 3 and $4 \mathrm{~km}$ ASL. This updraft region extended upward and northeastward, with another area of intense updrafts above $5.5 \mathrm{~km}$ ASL at $12-13 \mathrm{~km}$. A relatively tall convective region $(6 \mathrm{~km}$ ASL) was located adjacent to this area of intense updrafts. Another narrow updraft was located in 4-6 km ASL at $20 \mathrm{~km}$, coincident with another peak in the height of the convective region ( $6 \mathrm{~km} \mathrm{ASL).} \mathrm{Downdrafts} \mathrm{were} \mathrm{prevalent} \mathrm{below} 6 \mathrm{~km}$ ASL in the convective region at $10-17 \mathrm{~km}$ (Fig. 15d). The e-e transect (Fig. 15e) is oriented perpendicular to the convective region. Downdrafts dominated the convective region below $6 \mathrm{~km}$ ASL along the $\mathrm{e}-\mathrm{e}^{\prime}$ transect. A relatively wide updraft region $(15 \mathrm{~km})$ was located above $2 \mathrm{~km}$ ASL to the southeast of the convective region.

Figs. 14 and 15 indicated that the convective region strengthened significantly as it passed over the preexisting intense updraft region on the eastern slope of the island.

Fig. 16 shows vertical cross-sections along the $a-a^{\prime}, b-b^{\prime}$, c- $\mathrm{c}^{\prime}$, and d- $\mathrm{d}^{\prime}$ transect lines at 0120 LST, when the convective region moved to the eastern coastal area of the island. The locations of the transect lines are indicated in Fig. 13c. The a$a^{\prime}, b-b^{\prime}$, and $c-c^{\prime}$ transects are oriented parallel to the Jeju Island coastline and spaced at $5 \mathrm{~km}$ intervals. Along the a-a' transect (Fig. 16a), updrafts were prevalent above $2 \mathrm{~km}$ ASL between 15 and $20 \mathrm{~km}$. This region included an area of intense updrafts located above $3.5 \mathrm{~km}$ ASL over the land area. Convective region was located above $4.5 \mathrm{~km}$ ASL adjacent to the intense updrafts. The intense updraft and convective regions identified along the $a-a^{\prime}$ transect are not discernible along the $\mathrm{b}^{-\mathrm{b}^{\prime}}$ and $\mathrm{c}-\mathrm{c}^{\prime}$ vertical sections (Fig. 16b-c; 5 and $10 \mathrm{~km}$ north of $\mathrm{a}-\mathrm{a}^{\prime}$, respectively). The $\mathrm{d}-\mathrm{d}^{\prime}$ transect is oriented parallel to the southwesterly wind along the eastern slope of the island (Fig. 13c). Along the $\mathrm{d}-\mathrm{d}^{\prime}$ transect (Fig. 16d), the convective region extended from the surface to $2 \mathrm{~km}$ ASL with a downdraft region above it. Another convective region extended from 4 to $5 \mathrm{~km}$ ASL (14-16 km). A related updraft region that included intense updrafts was located above $3.5 \mathrm{~km}$ ASL to the southwest of the convective region $(5-15 \mathrm{~km})$.

During the lee-side stage, the convective region was significantly enhanced by local conditions on the eastern slope of the island. By contrast, the convective region that passed off the northeastern shore of the island weakened and dissipated. The significant enhancement of the convective region on the eastern slope was driven by the convergence of relatively weak westerly winds $\left(6 \mathrm{~ms}^{-1}\right)$ on the northeastern slope and strong southwesterly winds on the eastern slope of the island. These winds were consistent throughout the lee-side stage, and induced a localized updraft region over the eastern slope of the island. By contrast, the convective regions over the northeastern coastal area and off the northeastern shore were characterized by downdrafts and homogeneous westerly winds $\left(13 \mathrm{~ms}^{-1}\right)$.

\section{Discussion}

As presented in Sections 3 and 4, the convective region within the elongated precipitation system on 6 July 2007 evolved differently depending on its relative location to Jeju Island. The progression of this evolution can be divided into three stages: approaching stage, lateral-side stage, and lee-side stage. The structure and evolution of the portion of the convective region closest the lateral and lee sides of the island were different from those of the portion of the convective region located offshore, farther from the island. The distinguished features are discussed to understand the enhancement mechanism of the precipitation system for each of three stages.

\subsection{Evolution during the approaching stage}

During the approaching stage, the convective region of the precipitation system (defined as the area of radar reflectivity 

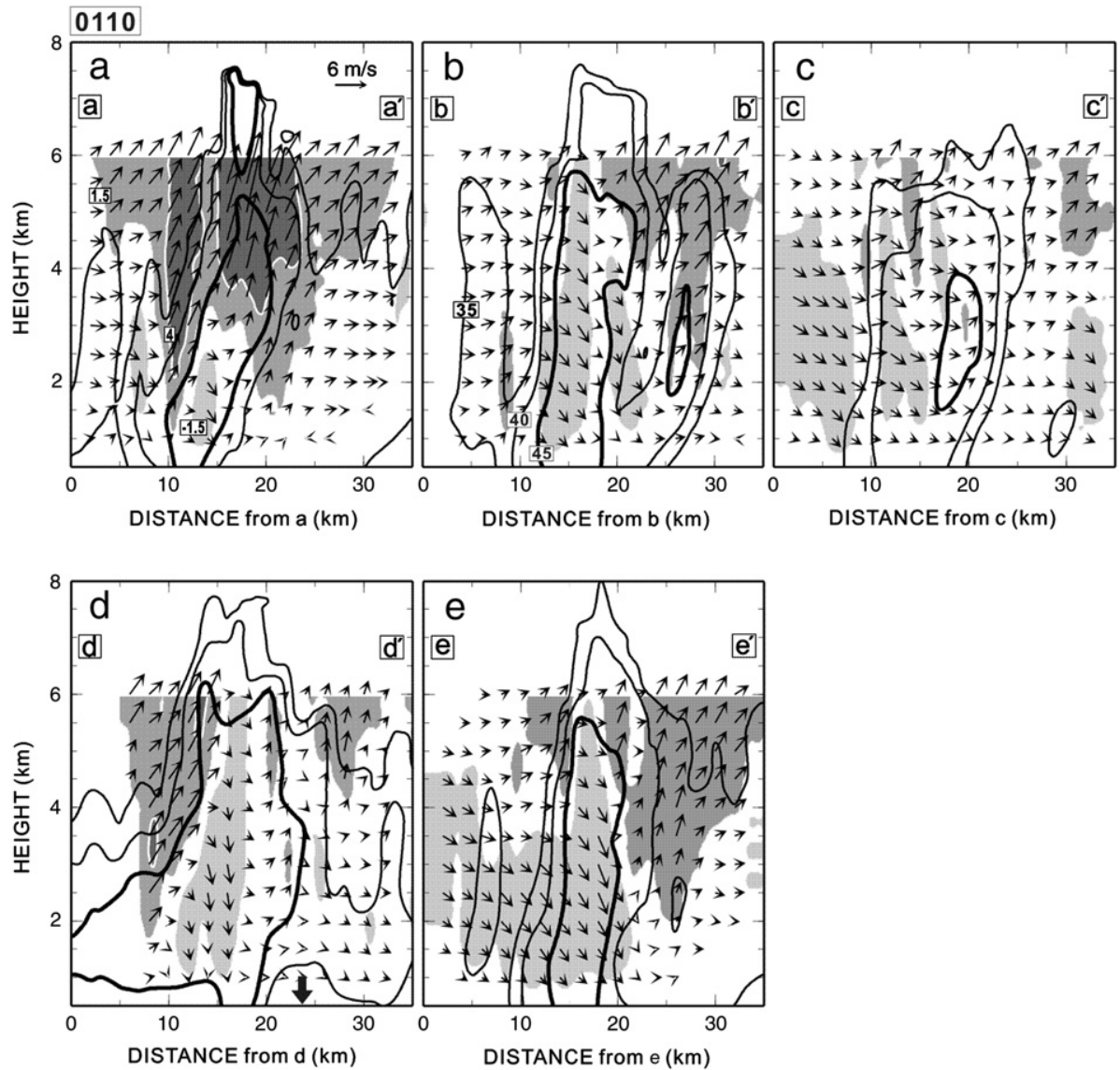

Fig. 15. Vertical cross-sections of reflectivity and system-relative winds at 0110 LST. The locations of the transect lines are shown in Fig. 13b. Transects a-a', b- $b^{\prime}$, and $c-c^{\prime}$ are oriented parallel to the horizontal axis of Fig. 13b. Transect $d-d^{\prime}$ is oriented perpendicular to the southwesterly wind. Transect e-e' is oriented perpendicular to the precipitation system. The shaded regions and contours are as in Fig. 8. A thick downward arrow on the horizontal axis in (d) indicates the location of the Jeju Island coastline.

greater than $45 \mathrm{dBZ}$ ) intensified significantly in the northwestern coastal area of the island. This intensification was evident in the expansion of the area of the convective region at $2 \mathrm{~km} \mathrm{ASL}$ from 10 to $60 \mathrm{~km}^{2}$ (Figs. 6 and $7 \mathrm{a}-\mathrm{d}$ ), and is shown in further detail in Fig. 17c as a time-height cross-section of maximum reflectivity. The heights of reflectivity in excess of $44 \mathrm{dBZ}$ increased gradually from 0000 to 0020 LST in the N2 (Fig. 17c; coast), N3 (Fig. 17b; offshore), and N4 (Fig. 17a; open sea) analysis domains. In $\mathbf{N 2}$, reflectivity in excess of $40 \mathrm{dBZ}$ was observed up to $8 \mathrm{~km} \mathrm{ASL}$, and the area of reflectivity greater than $48 \mathrm{dBZ}$ extended from the surface to $6 \mathrm{~km}$ ASL (Fig. 17c). A schematic illustration of this process is shown in Fig. 18a. An elongated updraft region (long hatched area in Fig. 18a) at the west of the convective region drove the gradual enhancement of the convective regions in $\mathbf{N 2}, \mathbf{N} 3$, and $\mathbf{N 4}$. This updraft region was induced by the convergence of strong westerlies from the western side and weak southwesterlies from the eastern side of the precipitation system (Fig. $7 \mathrm{f}-\mathrm{g}$ ). The strong enhancement of the convective region in N2 (Figs. 6, 7b-c, and $17 \mathrm{c}$ ) was driven by a localized updraft region (Fig. $7 \mathrm{j}-\mathrm{k}$; short hatched area in Fig. 18a) located between the southern part of the precipitation system and the island. This updraft region was related to an acceleration of southwesterly winds (Figs. 8a-b, e, 9f and i). The accelerated southwesterly winds in $\mathbf{N 2}$ appeared to correspond to the occurrence of strong reflectivity ( $50 \mathrm{dBZ}$ ) at altitudes above $4 \mathrm{~km}$ ASL in N3 (Figs. 8c, 9h and 17b).

As the precipitation system approached the island, the accelerated southwesterly winds and related updraft region between the system and the island appeared to have been essential to the significant enhancement of the system in the coastal area. This result is consistent with the results of a previous study by Wang et al. (2005). In their study, southwesterly winds prevailed offshore of the isolated, elliptical mountainous island of Taiwan. The approach of a convective line toward northwestern shore of the island with a Froude number $(F r)$ of 0.25 accelerated the southwesterly wind and generated a localized updraft region between the southern edge of the convective line and the high terrain of the island. As a result, the southern part of the convective line intensified significantly, particularly compared to the northern part. Though Jeju Island has relatively small horizontal scale compared to Taiwan, with a similar $\mathrm{Fr}(0.2)$, the acceleration of the southwesterly wind and the generation of an updraft region between the precipitation system and the mountainous terrain are common elements to both locations. These elements appear to be crucial for the enhancement of a system approaching an elliptically-shaped topographic feature. 


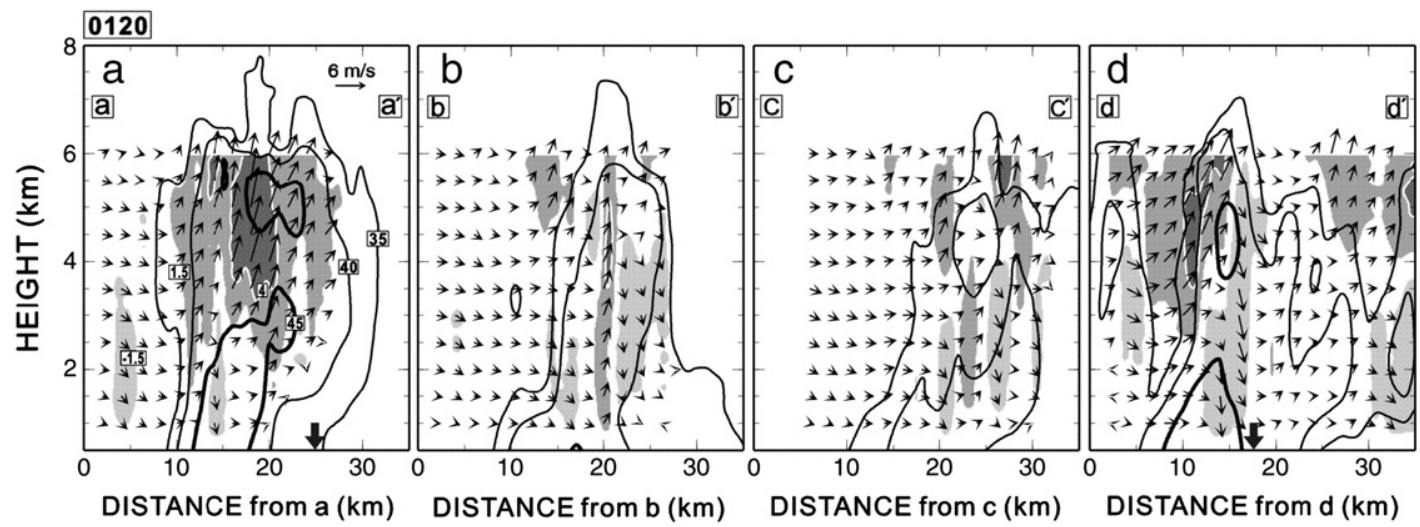

Fig. 16. Vertical cross-sections of reflectivity and system-relative winds at 0120 LST. The locations of the transect lines are shown in Fig. $13 c$. Transects a-a', b-b', and $c-c^{\prime}$ are oriented parallel to the Jeju Island coastline. Transect $d-d^{\prime}$ is oriented parallel to the southwesterly wind. The shaded regions and contours are as in Fig. 8. The thick downward arrows on the horizontal axes in (a) and (d) indicate the location of the coastline.

The localized updraft region was sustained by a relatively weaker southwesterly wind even after the convective region arrived on the northwestern part of the island (Figs. 7h, 1, and 9f), inducing the continued enhancement of the portion of the convective region that was located over the coastal area. This importance of a southwesterly wind over the northwestern part of the island was also found by Lee et al. (2010). In their study, which identified a Fr of 0.55 , winds were rerouted both horizontally and vertically around Jeju Island. A portion of the horizontally-rerouted wind played an important role in enhancing rainfall over the northwestern part of the island by converging with the predominant westerly winds to generate a local updraft. In this study, in which $F r$ is 0.2 , the prevailing westerly winds are expected to be rerouted to travel around the mountain over the northwestern part of the island, generating southwesterly winds. These southwesterly winds provide a plentiful supply of moist air to the convective region at low altitudes. The local updraft induced by convergence of the predominant westerly and terrain-induced southwesterly winds therefore appears to play an important role in maintaining the enhancement of the precipitation system over the northwestern coastal of the island.

\subsection{Evolution during the lateral-side stage}

Following its intensification in the northwestern coastal area of the island, the convective region maintained its intensity as it moved along the northern lateral side of the island. The horizontal area of the convective region was consistently $60-65 \mathrm{~km}^{2}$ at $2 \mathrm{~km}$ ASL during this stage of the system's evolution (Figs. 6 and 10a-b). Moreover, the height of reflectivity in excess of $48 \mathrm{dBZ}$ was approximately $6 \mathrm{~km}$ ASL during the lateral-side stage, the same as that found during the approaching stage (Fig. 17c). The schematic illustration of this stage is shown in Fig. 18b. While the convective region was located on the northern lateral side of the island, the terrain-induced southwesterly winds extended to the northern part of the island. This extension maintained the supply of low-altitude moist air to the convective region. The generation and maintenance of local updrafts by the convergence of the predominant westerly and terrain-modified southwesterly winds allowed the convective region to retain its intensity (Figs. 10c-f, 11a-b, $12 \mathrm{f}$, and 18b). This continuous upward air motion corresponds to the area of reflectivity in excess of $50 \mathrm{dBZ}$ above $5 \mathrm{~km}$ ASL in N2 (Fig. 17c).

\subsection{Evolution during the lee-side stage}

During the lee-side stage, the area of the convective region at $2 \mathrm{~km}$ ASL in $\mathbf{N 1}$ increased significantly over the eastern slope of the island, from 15 to $55 \mathrm{~km}^{2}$ (Figs. 6 and $13 \mathrm{a}-\mathrm{c})$. This significant enhancement of the convective region is shown in Fig. 17d and illustrated schematically in Fig. 18c. The height of $40 \mathrm{dBZ}$ reflectivity increased to $7.5 \mathrm{~km}$ ASL and that of strong reflectivity ( $48 \mathrm{dBZ}$ ) increased to $4 \mathrm{~km}$ ASL (Fig. 17d). A locally generated stationary updraft region was important for the significant enhancement of the convective region on the lee side of the island (Figs. 13h-i, $14 \mathrm{a}, \mathrm{d}, 15 \mathrm{a}, \mathrm{d}$, and 18c). This stationary updraft region was generated by the convergence of weak westerlies from the northern part of the island and strong southwesterlies from the southeastern slope of the island (Figs. 13e-f, 18c). The relatively strong southwesterly winds (which blew over mountain ridges with elevations of less than $500 \mathrm{~m}$ ) provided plentiful moisture to the convergence zone and related updrafts. Although the wind field observations are restricted on the southern slope of the mountain due to the limited observational range of the dual-Doppler radars, the updraft region induced by these relatively strong southwesterly winds can be inferred from the following. First, the local updraft region on the eastern slope of the island existed prior to and ahead of the eastward-moving convective region (Figs. 13h-i, 14a, d, 15a, and d). This updraft region was continuously observed as the convective region approached the eastern part of the island. Second, as the convective region passed the locally generated updraft region on the eastern slope, the convective region extended southwestward at $2 \mathrm{~km}$ ASL (Figs. 13a-b and 15d). This enlarged area of the convective region at $2 \mathrm{~km}$ ASL from 15 to $55 \mathrm{~km}^{2}$ over the eastern part of the island (Fig. 6). The plentiful 

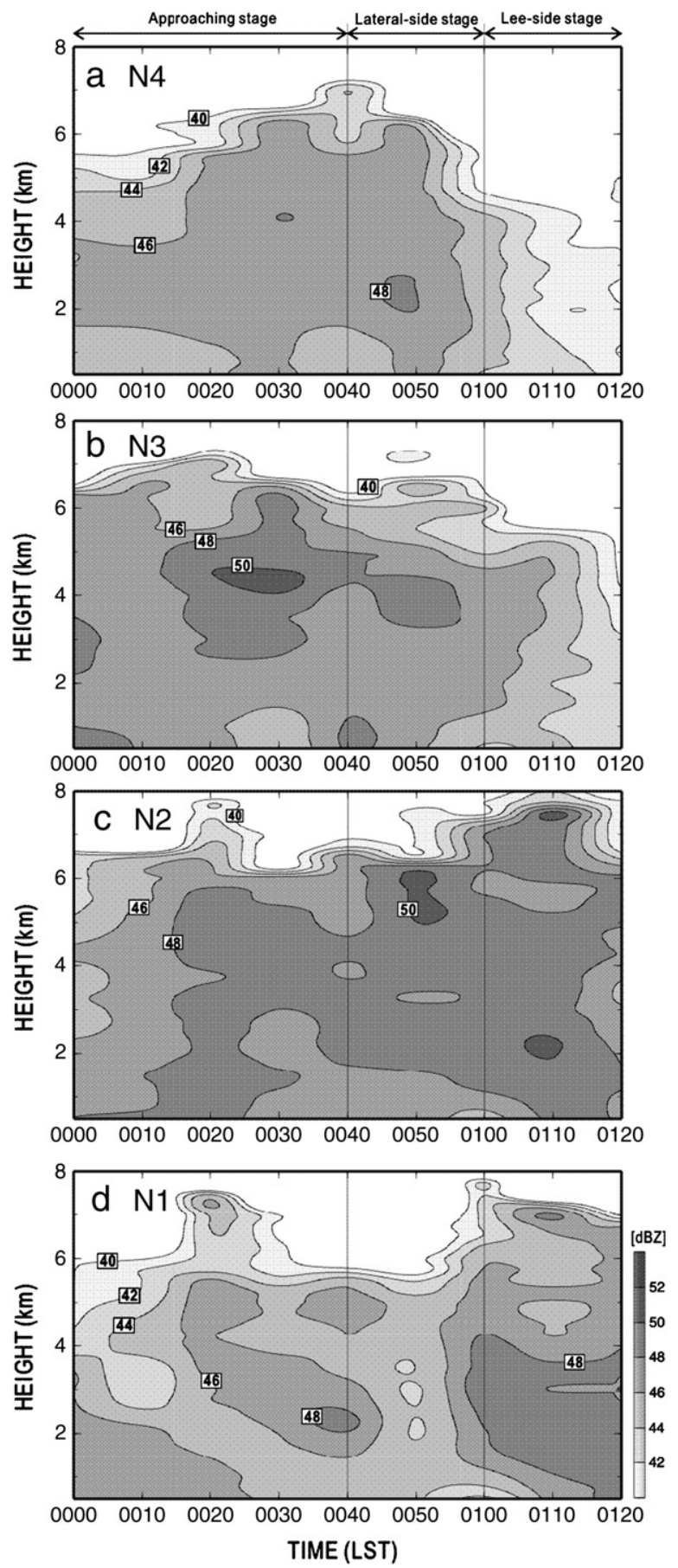

Fig. 17. Time-height cross-section of maximum reflectivity from 0000 to 0120 LST in the analysis domains (a) N1 (over land), (b) N2 (coastal), (c) N3 (offshore), and (d) N4 (open sea). The boundaries of the analysis domains are depicted in Fig. 5. Contours and shading show reflectivity at intervals of 2 $\mathrm{dBZ}$ starting from $40 \mathrm{dBZ}$.

supply of moist air at low altitudes and the stationary local updraft reinforced the convective region. Third, the region of intense updrafts was extended to the northeastern slope of the island by the strong southwesterly winds, as evidenced by the area of high reflectivity (greater than $50 \mathrm{dBZ}$ ) located at relatively high altitude ( $\sim 7 \mathrm{~km}$ ASL) in the northeastern coastal area of the island (N2, Fig. 17c).

This study finds that the convective region re-intensified on the lee-side of the island. This is in contrast to the results of Lee et al. (2010), who described a precipitation system that dissipated as it moved to the lee side of Jeju Island on 30 June 2006. Their results showed relatively strong ambient westsouthwesterly winds at low altitudes with a Fr of 0.55 . Under these conditions, a portion of the wind passed over the mountain, generating a downdraft region over the northeastern part of the island. These downdrafts cut off the low-level moist air provided by a portion of horizontally-rerouted winds. The convective region moved toward this preexisting downdraft region on the lee-side of the island, then dissipated. Comparison of the results of this study with those of Lee et al. (2010) suggests that, even in similar moist rainy season conditions with similar ambient west-southwesterly winds, the two precipitation systems evolved differently as they reached the lee-side of the island. These different system evolutions may be explained by differences in the low-level wind speeds. The relatively weak low-level winds $(F r=0.2)$ in this study detoured horizontally and arrived over the lee-side of the island generating updraft region with relatively strong southwesterly winds from the southeastern part of the island. These winds resulted in a locally generated updraft region. These conditions induced an intensification of the convective region on the lee-side of the island. In the study by Lee et al. (2010), relatively strong low-level winds $(F r=0.55)$ resulted in a partial vertical detour of the winds over the central mountain. This generated a dry downdraft on the northeastern (lee) slope of the mountain, which in turn resulted in the dissipation of the convective region as it reached the lee-side of the island. These results suggest that the speed of the ambient west-southwesterly winds at low altitudes is an important parameter for determining the evolution of the convective region on the lee-side of the island.

The key points of this paper are summarized below.

1) A preexisting elongated precipitation system (oriented southwest-northeast) and an isolated elliptical mountain on Jeju Island (oriented west-east) induced accelerated southwesterly winds, convergence, and localized updrafts off the northwestern shore of the island as the system approached. Moist atmospheric conditions at low altitudes during the rainy season and the localized updraft between the system and the island combined to cause a dramatic enhancement in the southern part of the precipitation system.

2) The isolated elliptically-shaped terrain of Jeju Island played a role in modifying the low-level wind with a relatively low $\mathrm{Fr}$ of 0.2 . The horizontal rerouting of the wind at low altitudes by the terrain worked in concert with low-level moist air during the rainy season, resulting in further enhancement of the convective region as the system passed over the northwestern part of the island.

3) The terrain-modified low-level winds provided a plentiful supply of moist air into the enhanced convective region as the precipitation system passed around the northern part of the island. These environmental conditions acted to maintain the intensity of the convective region. 


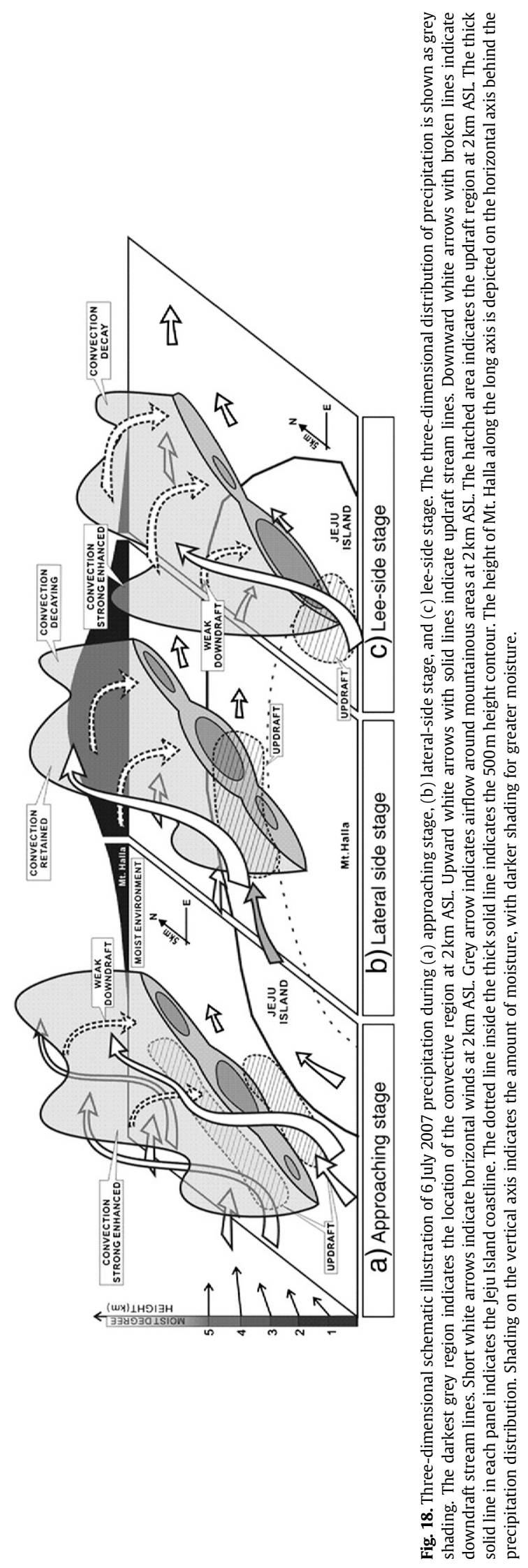


4) Relatively strong southwesterly wind coming over the southeastern slope of the island (height less than $500 \mathrm{~m}$ ) generated a stationary local updraft over the eastern part of the island. The convergence of the relatively strong and moist southwesterly winds with the prevailing westerly winds caused the convective region to again intensify significantly as it passed over the lee-side of the island.

In summary, an elongated precipitation system associated with a stationary front evolved in remarkable ways as it passed over the northern side of Jeju Island on 6 July 2007. On particularly noteworthy point is the persistence of the convective region that passed near the island compared to that the persistence of the convective region that passed over the sea off the northern coast of the island. The terrain-modified wind provided a plentiful supply of moist air to the northern side of the island. This supply of moist air by strong southwesterly flow also played an important role in the further intensification of the convective region on the lee-side of the island. Comparison of these results with those of Lee et al. (2010) suggests that a moist environment and ambient west-southwesterly winds are well organized when a stationary front is located off the northern shore of Jeju Island. These ambient conditions are favorable for triggering the intensification of a convective region on the northern lateral side of an elliptical mountain with a steep slope. Even in similar environmental conditions, the speed of the ambient low-altitude wind plays an important role in determining the evolution of the system on the lee-side of the island. Further studies into what determines the evolution of precipitation systems on the lee-side of this island will be necessary using both observational data and numerical simulations.

\section{Conclusions}

An elongated precipitation system strengthened significantly on the northern lateral and lee sides of an isolated mountain on Jeju Island on 6 July 2007. At 0300 LST, a stationary front (the Changma/Baiu/Meiyu front) was located slightly north of the island. The RH at $950 \mathrm{hPa}$ in the vicinity of the island was relatively high (greater than 94\%). Upper-air sounding data indicates that approximately 65\% of the atmospheric moisture content (PW, $42 \mathrm{~kg} \mathrm{~m}^{-2}$ ) was concentrated at low levels (below $700 \mathrm{hPa}$ ).

Detailed 3-dimensional radar data indicates that the isolated mountain and elliptical shape of Jeju Island modified the prevailing winds, generating local updrafts. These local updrafts played an important role in intensifying the southern part of an elongated precipitation system as it passed around the northern part of the mountain in a moist ambient environment.

As the system approached the island from the northwest, southwesterly winds accelerated and induced regional updrafts between the southern part of the system and the island. These updrafts were a crucial component in the initial significant enhancement of the convective region. Furthermore, the isolated and elliptical terrain of Jeju Island modified the low-level wind blowing around the terrain with a relatively low $F r$ of 0.2 . This modification of the low-level winds drove the further intensification of the convective region, as the rerouted winds provided a steady supply of moist air to the convective region. After this intensification, the convective region moved to the northern lateral side of the island. The modification of the prevailing winds by the terrain was most consistently observed on the northern lateral side of the island; this configuration of the low-level winds allowed the convective region to retain its intensity. The convective region then moved to the lee-side of the island, where it again intensified significantly. Weak westerlies from the northern lateral side of the island and stronger, moist southwesterlies from the southeastern slope of the island induced a local updraft region over the lee-side of the island. The second enhancement of the convective region occurred as it passed over these locally generated updrafts.

The eastward-moving precipitation system of 6 July 2007 was enhanced locally and significantly on the lateral and lee sides of Jeju Island by orographically generated updrafts. This enhancement took place under the prevailing moist environment during the rainy season. This moist environment and the ambient west-southwesterly winds observed throughout the passage of this system are well-organized features when a stationary front is located off the northern shore of Jeju Island. These conditions favor the significant enhancement of precipitation systems as they pass along the northern coast of Jeju Island.

\section{Acknowledgements}

This work was funded by the Korea Meteorological Administration Research and Development Program under Grant CATER 2012-2071. This work is also partially supported by Grant-in-Aid for Scientific Research defrayed by the Ministry of Education, Culture, Sports, Science and Technology of Japan (24253006). One of the authors (Keun-Ok Lee) is supported by the Ministry of Education, Culture, Sports, Science, and Technology, Japan, as a doctoral student in the Graduate School of Environmental Studies, Nagoya University, Japan. The authors thank Dr. K. Tsuboki, Dr. T. Shinoda and members of the Laboratory of Meteorology of HyARC, Nagoya University, for their fruitful discussion; Dr. C.-H. You, Korean Meteorological Administration, for his help in obtaining the data and providing fruitful advice on the radar analyses; and Dr. M. Maki, Dr. R. Misumi, Dr. S. Suzuki, Dr. D.-S. Kim, Dr. Y. Shusse and Dr. N. Sakurai at National Research Institute for Earth Science and Disaster Prevention in Japan for their valuable suggestions.

\section{References}

Chen, G.T.J., Chang, C.P., 1980. The structure and vorticity budget of an early summer monsoon trough (Mei-Yu) over southeastern China and Japan. Mon. Weather Rev. 108, 942-953.

Chiao, S., Lin, Y.-L., 2003. Numerical modeling of an orographically enhanced precipitation event associated with tropical storm Rachel over Taiwan. Weather Forecast. 18, 325-344.

Cressman, G.P., 1959. An operational objective analysis system. Mon. Weather Rev. 87, 367-374.

Gao, J., Xue, M., Shapiro, A., Droegemeier, K.K., 1999. A variational method for the analysis of three-dimensional wind fields from two Doppler radars. Mon. Weather Rev. 127, 2128-2142.

Geng, B., Yamada, H., Reddy, K.K., Uyeda, H., Fujiyoshi, Y., 2009. Mesoscale development and along-frontal variation of a Meiyu/Baiu front and precipitation observed in the downstream region of the Yangtze River. J. Meteorol. Soc. Jpn. 87, 423-457. 
Georgelin, M., Richard, E., 1996. Numerical simulation of flow diversion around the Pyrenees: A tramontana case study. Mon. Weather Rev. 124, 687-700.

Houze Jr., R.A., 2011. Orographic effects on precipitating clouds. Rev. Geophys., http://dx.doi.org/10.1029/2011RG000365.

Jiang, Q., 2003. Moist dynamics and orographic precipitation. Tellus 55A, 301-316.

Kato, K., 1985. On the abrupt change in the structure of the Baiu front over the China continent in late May of 1979. J. Meteorol. Soc. Jpn. 63, 20-36.

Lee, K.-O., Shimizu, S., Maki, M., You, C.-H., Uyeda, H., Lee, D.-I., 2010 Enhancement mechanism of the 30 June 2006 precipitation system observed over the northwestern slope of Mt. Halla, Jeju Island, Korea. Atmos. Res. 97, 343-358.

Li, J., Chen, Y.-L., Lee, W.-C., 1997. Analysis of a heavy rainfall event during TAMEX. Mon. Weather Rev. 125, 1060-1082.

Lin, Y.-L., 2007. Mesoscale dynamics. Cambridge University Press. 630 pp.

Ninomiya, K., Muraki, H., 1986. Large-scale circulations over East Asia during Baiu period of 1979. J. Meteorol. Soc. Jpn. 64, 409-429.

Ogura, Y., 1991. Analyses and mechanisms of intense precipitation. Tenki 38, 276-288 (in Japanese).

Olafsson, H., 2000. The impact of flow regimes on asymmetry of orographic drag at moderate and low Rossby numbers. Tellus 52A, 365-379.

Olafsson, H., Bougeault, P., 1996. Nonlinear flow past an elliptic mountain ridge. J. Atmos. Sci. 53, 2465-2489.

Olafsson, H., Bougeault, P., 2000. The impact of flow regimes on asymmetry of orographic drag at moderate and low Rossby numbers. Tellus 52A, 365-379.

Olanski, I., 1975. A rational subdivision of scales for atmospheric processes. Bull. Am. Meteorol. Soc. 56, 527-530.
Petersen, G.N., Olafsson, H., Kristjansson, J.E., 2003. Flow in the lee of idealized mountains and Greenland. J. Atmos. Sci. 60, 2183-2195.

Petersen, G.N., Olafsson, H., Kristjansson, J.E., Kristjansson, J.E., Olafsson, H., 2005. The effect of upstream wind direction on atmospheric flow in the vicinity of a large mountain. Q. J. R. Meteorol. Soc. 131, 1113-1128.

Smith, R.B., 1979. The influence of mountains on the atmosphere. Adv. Geophys. 21, 87-230.

Smith, R.B., 1980. Linear theory of stratified hydrostatic flow past an isolated mountain. Tellus 32, 348-364.

Smolarkeiwicz, P.K., Rasmussen, R.M., Clark, T.L., 1988. On the dynamics of Hawaiian cloud bands: island forcing. J. Atmos. Sci. 45, 1872-1905.

Smolarkeiwicz, P.K., Rotunno, R., 1989. Low Froude number flow past threedimensional obstacles. PartI: Baroclinically generated Lee vortices. J. Atmos. Sci. 46, 1154-1164.

Smolarkeiwicz, P.K., Rotunno, R., 1990. Low Froude number flow past threedimensional obstacles. PartII: upwind flow reversal zone. J. Atmos. Sci. 47, 1498-1511.

Wang, C.-C., Chen, G.T.-J., Chen, T.-C., Tsuboki, K., 2005. A numerical study on the effects of Taiwan topography on a convective line during the Mei-Yu season. Mon. Weather Rev. 133, 3217-3242.

Yamada, H., Geng, B., Reddy, K.K., Uyeda, H., Fujiyoshi, Y., 2003. Threedimensional structure of a mesoscale convective system in a Baiu-frontal depression generated in the downstream region of the Yangtze River. J. Meteorol. Soc. Jpn. 81, 1243-1271.

Yoshizaki, M., Kato, T., Tanaka, Y., Takayama, H., Shoji, Y., Seko, H., Arao, K., Manabe, K., 2000. Analytical and numerical study of the 26 June 1998 orographic rainband observed in western Kyushu, Japan. J. Meteorol. Soc. Jpn. 78, 835-856. 